\title{
No Ecological Opportunity Signal on a Continental Scale? Diversification and Life-History Evolution of African True Toads (Anura: Bufonidae)
}

\begin{tabular}{|c|c|}
\hline Journal: & Evolution \\
\hline Manuscript ID & 15-0911.R1 \\
\hline Manuscript Type: & Original Article \\
\hline Date Submitted by the Author: & $\mathrm{n} / \mathrm{a}$ \\
\hline Complete List of Authors: & $\begin{array}{l}\text { Liedtke, Christoph; Doñana Biological Station EBD-CSIC, Department of } \\
\text { Wetland Ecology; University of Basel, Institute of Biogeography } \\
\text { Müller, Hendrik; Friedrich-Schiller-Universität, Institut für Spezielle } \\
\text { Zoologie und Evolutionsbiologie mit Phyletischem Museum } \\
\text { Rodel, Mark-Oliver; Museum für Naturkunde, Leibniz Institute for Evolution } \\
\text { and Biodiversity Science } \\
\text { Menegon, Michele; MUSE- Museo delle Scienze, Tropical Biodiversity } \\
\text { Section } \\
\text { Gonwouo, LeGrand; Cameroon Herpetology-Conservation Biology } \\
\text { Foundation } \\
\text { Barej, Michael; Museum für Naturkunde, Leibniz Institute for Evolution and } \\
\text { Biodiversity Science } \\
\text { Gvoždík, Václav; Institute of Vertebrate Biolog, Czech Academy of Sciences } \\
\text { Schmitz, Andreas; Muséum d'Histoire Naturelle, Department of } \\
\text { Herpetology and Ichthyology } \\
\text { Channing, Alan; University of the Western Cape, Biodiversity and } \\
\text { Conservation Biology Department } \\
\text { Nagel, Peter; University of Basel, Department of Environmental Science } \\
\text { (Biogeography) } \\
\text { Loader, Simon; University of Basel, Institute of Biogeography; University of } \\
\text { Roehampton, Department of Life Sciences }\end{array}$ \\
\hline Keywords: & $\begin{array}{l}\text { Amphibia, evolutionary rate dynamics, disparity, BAMM, bGMYC, molecular } \\
\text { phylogeny }\end{array}$ \\
\hline
\end{tabular}


1 No Ecological Opportunity Signal on a Continental Scale? Diversification and Life-History

2 Evolution of African True Toads (Anura: Bufonidae)

3 H. Christoph Liedtke ${ }^{1,2}$, Hendrik Müller ${ }^{3}$, Mark-Oliver Rödel ${ }^{4}$, Michele Menegon ${ }^{5}$, LeGrand

4 Nono Gonwouo ${ }^{6}$, Michael F. Barej ${ }^{4}$, Václav Gvoždík ${ }^{7}$, Andreas Schmitz $^{8}$, Alan Channing ${ }^{9}$,

$6{ }^{1}$ Department of Environmental Science (Biogeography), University of Basel,

$7 \quad$ Klingelbergstrasse 27, 4056 Basel, Switzerland

$8{ }^{2}$ Ecology, Evolution and Developmental Group, Department of Wetland Ecology, Estación

9 Biológica de Doñana (CSIC), 41092 Sevilla, Spain

$10{ }^{3}$ Institut für Spezielle Zoologie und Evolutionsbiologie mit Phyletischem Museum, Friedrich-

11 Schiller-Universität Jena, Erbertstraße 1, 07743 Jena, Germany

$12{ }^{4}$ Museum für Naturkunde Berlin, Leibniz Institute for Evolution and Biodiversity Science,

13 Invalidenstraße 43, 10115 Berlin, Germany

$14{ }^{5}$ Tropical Biodiversity Section, MUSE-Museo delle Scienze, Corso del Lavoro e della Scienza

15 3, Trento 38123, Italy

$16{ }^{6}$ Cameroon Herpetology-Conservation Biology Foundation, P.O. Box 8218, Yaoundé,

17 Cameroon

$18{ }^{7}$ Institute of Vertebrate Biology, Czech Academy of Sciences, Květná 8, 60365 Brno, Czech

19 Republic

$20{ }^{8}$ Natural History Museum of Geneva, Department of Herpetology and Ichthyology, C.P. 6434,

211211 Geneva 6, Switzerland

$22{ }^{9}$ Biodiversity and Conservation Biology Department, University of the Western Cape, Private

23 Bag X17, Bellville, 7535, South Africa

$24{ }^{10}$ Department of Life Sciences, University of Roehampton, London SW15 4JD, United Kingdom 
26 Running head: Diversification of African Bufonids

27 Keywords: Amphibia, evolutionary rate dynamics, disparity, BAMM, bGMYC, molecular 28 phylogeny

29 


\section{Abstract}

31 The niche-filling process predicted by the 'ecological opportunity' (EO) model is an often-invoked

32 mechanism for generating exceptional diversity in island colonizers. Whether the same process

33 governs the lineage accumulation and trait disparity during continental colonization events is less

34 clear. Here we test this prediction by investigating the rate dynamics and trait evolution of one of

35 Africa's most widespread amphibian colonizers, the true toads (Bufonidae). By reconstructing the

36 most complete molecular phylogeny of African Bufonidae to date, we find that the diversification of

37 lineages in Africa has been constant throughout time and across subclades, with little support for

38 early-burst diversification. Evolutionary rates of life history traits have similarly been constant over

39 time. However, an analysis of generalists and specialists showed a shift towards higher speciation

40 rates associated with habitat specialization. The overall lack of EO signal can be interpreted in a

41 number of ways and we propose several not mutually exclusive explanations. Firstly, methodological

42 issues might preclude the detection of EO, secondly colonizers might not experience true EO

43 conditions and due to the size, ecological heterogeneity and age of landmasses, the diversification

44 processes might be more complex, thirdly lower speciation rates of habitat generalists may have

45 affected overall proliferation of lineages.

\section{Introduction}

48 How species and species assemblages respond to a release from ecological competition is a key

49 question in evolutionary biology (Simpson 1953; Schluter 2000; Losos 2010; Yoder et al. 2010). The

50 colonization of islands (Robichaux et al. 1990; Grant 1999; Whittaker and Fernandez-Palacios 2007),

51 mass extinction events (Sepkoski 1998), the availability of new resources (McKenna et al. 2009) or

52 the evolution of key innovations (Hunter and Jernvall 1995; Jønsson et al. 2012) are classic examples

53 of where a sudden intrinsic or extrinsic change has presented organisms with an 'ecological

54 opportunity' (EO; Simpson 1953). In response to this opportunity, lineages are predicted to rapidly 
55 diversify, unimpeded by competition until an ecological saturation point is reached inducing a

56 slowdown in diversification (Nee et al. 1992; Rabosky 2009a). Phylogenies are a powerful tool for

57 the inference of macroevolutionary processes (Mooers and Heard 1997) and the detection of diversity

58 dependent lineage accumulation patterns in response to competitive release has been interpreted as a

59 signal for EO, especially in relation to adaptive radiations (Losos and Mahler 2010). Diversifying

60 into new niche space when presented with EO should also be reflected in the diversification and

61 disparity of phenotypes (Simpson 1953; Schluter 2000; Harmon et al. 2003; Slater et al. 2010;

62 Jønsson et al. 2012), especially in traits relevant to adaptation (Steelman and Danley 2003).

63 Reconstructing the evolutionary history of phenotypes can therefore strongly complement our

64 understanding of diversification from studying phylogenies (Mahler et al. 2010; Harmon et al. 2010;

65 Slater et al. 2010).

Ecological opportunity is often cited as an important precondition for generating exceptional

67 levels of biodiversity (Schluter 2000; Losos 2010), but most empirical studies on EO are focused on

68 insular (Grant 1999; Harmon et al. 2008a; Jønsson et al. 2012), or localized mainland systems

69 (Hughes and Eastwood 2006; Kozak and Wiens 2006; Pinto et al. 2008; Rabosky and Lovette 2008a;

70 Slingsby et al. 2014; Price et al. 2014b). Yet, continental systems are often more diverse than their

71 island counterparts (Whittaker and Fernandez-Palacios 2007; Pinto et al. 2008) and whether the same

72 processes can generate bursts in biodiversity on a continent-wide scale has only recently begun to

73 receive attention. Some of these studies have yielded support for EO as a key mechanism for

74 producing exceptional biodiversity (Burbrink and Pyron 2009; Barker et al. 2013; Schenk et al. 2013,

75 although not always; Price et al. 2014a), even showing multiple EO events nested across subclades

76 (Drummond et al. 2012b; McGuire et al. 2014), while others have not detected EO signals

77 (Derryberry et al. 2011; Claramunt et al. 2012b; Day et al. 2013; Schweizer et al. 2014; Alhajeri et al.

78 2015), and a general consensus on the role of ecological limits for diversification is lacking (Harmon

79 and Harrison 2015; Rabosky and Hurlbert 2015). 
In continent-wide studies of EO, detections of both rapid and early lineage and trait

81 diversification has been attributed to the biogeographic transition to new, underutilized areas as a

82 result of a colonization event (Burbrink and Pyron 2009; Barker et al. 2013; Schenk et al. 2013; Price

83 et al. 2014a). Conversely, a lack of signal has been attributed to the geographic and ecological

84 complexity of continents, with ecological saturation unlikely to occur on such a scale (Derryberry et

85 al. 2011; Day et al. 2013; Schweizer et al. 2014). Furthermore, the dispersal ability of ancestors that

86 may have led to the continent-wide colonization of new habitats may in itself inhibit rapid speciation

87 by preventing ecological isolation (Claramunt et al. 2012b). EO as a result of expansion into new

88 geographic or ecological space may therefore be as much a driver for generating biodiversity in

89 continent-wide clades as is the case for island or localized mainland radiations, but high dispersal

90 ability or the magnitude of the ecological carrying capacity of continents could equally mean that the

91 EO model is less applicable to such geographically and ecologically more complex systems.

92 Alternatively, if indeed EO played a role in shaping diversification, these systems may be too old for

93 early burst signals to be detectable if changes in rate over time were not drastic or if too much time

94 has passed since rate equilibrium has been reached (Liow et al. 2010; Rabosky and Hurlbert 2015).

With 586 currently recognized species worldwide, Bufonidae is the third most species-rich

96 family of amphibians (Frost 2016). Unlike most other amphibians, bufonids were able to colonize

97 most parts of the world (Duellman 1999) and this species-rich and world-wide diversification across

98 entire continents offers an excellent system for investigating how biodiversity accumulates on

99 continents and whether early bursts in both lineage accumulation and trait disparity has occurred as a

100 response to EO. African bufonids in particular are suitable for addressing EO, firstly, due to extreme

101 trait disparity observed across species. Variable phenotypic traits include body size (19-163 mm;

102 Liedtke et al. 2014), which is correlated with ecological factors and under strong selection in many

103 systems (Davis 1938; Peters 1986). Furthermore, diverse modes of life history strategies (biphasic

104 aquatic breeding to viviparity) are evident in African bufonids (Liedtke 2014; Liedtke et al. 2014) 
and components of these, such as fecundity (clutch size) and parental investment per offspring (egg

106

107

108

109

110

111

112

113

114

115

116

117

size), are good indicators for adaptation to extrinsic factors (Dobzhansky 1950; Duellman and Trueb 1994; Roff 2002; Räsänen et al. 2008). A second qualification is the biogeographic transition African bufonids underwent. Both fossil and molecular evidence point to a Neotropical origin of Bufonidae (Tihen 1962; Blair 1972; Pramuk et al. 2008) at around 80-60 Ma (Pramuk et al. 2008; Van Bocxlaer et al. 2010) followed by a rapid global diversification earliest in the Late Eocene (40-30 Ma; Pramuk et al. 2008; Van Bocxlaer et al. 2010; Portik and Papenfuss 2015). By the Oligocene ( $30 \mathrm{Ma})$ bufonids were established on all continents except Australia and Antarctica (Van Bocxlaer et al. 2010), neither of which host endemic bufonid lineages at present. Van Bocxlaer et al. (2010) proposed that the evolution of an 'optimal range-expansion phenotype' (robust, explosive breeders with high dispersal abilities) was crucial for their success, a phenotype they estimated as characteristic of the first lineage to colonize Africa as well. Their broad ecological tolerance may have been advantageous for allowing this group to disperse widely on the continent, but such habitat generalism may ultimately result in lower overall lineage proliferation (Claramunt et al. 2012a).

Nonetheless, African bufonids display a rich array of phenotypes, reproductive behaviour and habitat preferences (Tandy and Keith 1972; Clarke 2001; Liedtke et al. 2014), which raises the question whether this diversity was spurred by EO.

By assembling the largest molecular and trait dataset for African bufonids to date, including numerous candidate taxa so far not formally described, we test whether the colonization of Africa by toads has left signals characteristic of the EO model. Under this model we expect to find an early burst of lineage accumulation and life history trait disparity with a subsequent slowdown in rates. We also investigate whether habitat generalists have experienced different speciation rates compared to habitat specialists.

\section{Methods}


130 An extended version of the methods employed can be found as Supporting Information S1 and is

131 summarized in brief here.

\section{Taxon Sampling and DNA Sequencing}

134 The number of currently recognized species of African Bufonidae (101, see extended methods S1) is 135 unlikely to be the true number of species due to the questionable taxonomic validity of some (Tandy 136 and Keith 1972; Poynton 1997; Rödel 2000; Rödel and Branch 2003) and the large number of

137 candidate species awaiting formal taxonomic treatment (Tandy and Keith 1972; Poynton and

138 Broadley 1988; Tolley et al. 2010). Taxon sampling has therefore been extensive to include at least

139 one representative of every African genus and as many geographic localities as possible per species.

140 In total, 1676 sequences from 432 individuals were generated de novo for this study, and in

141 combination with sequence data from GenBank, the complete dataset includes 591 individuals of at

142 least 112 species including non-African outgroups. This covers almost $70 \%$ of all described African

143 species (69 out of 101), 14 out of 18 Eurasian genera and a selection of New World bufonids to

144 provide wider phylogenetic context and to allow for the inclusion of more fossil calibration points.

145 DNA was extracted from preserved tissue, using a Qiagen DNeasy Blood and Tissue Kit

146 (Qiagen Inc., CA, USA) and the default protocol. A total of $\sim 3439$ base pairs comprising five

147 markers including partial sequences of two ribosomal RNA genes; 12S and 16S rRNA ( $\sim 380$ and

$148 \sim 575 \mathrm{bp}$ ), and three coding regions: cytochrome-oxidase subunit 1 (COI; mitochondrial, $\sim 840$ bp), C-

149 X-C chemokine receptor type 4 (CXCR4; nuclear, $711 \mathrm{bp}$ ), and recombination activating gene-1

150 (RAG1; nuclear, 933 bp) were amplified via Polymerase Chain Reaction (PCR) using Illustra

151 puReTaq Ready-To-Go PCR beads (GE healthcare, Buckinghamshire, UK). PCR products were

152 sequenced by Microsynth AG (Balgris, $\mathrm{CH}$ ), complementary strands were sequenced for

153 proofreading and all sequences were deposited in GenBank (Supporting Information S2). 
156 Sequences were processed using the Codoncode Aligner v4.4.1 (Codoncode Cooperation, MA, USA)

157 and Geneious Pro v5.6.7 (www.geneious.com; Kearse et al. 2012). Each gene region was aligned

158 separately with MAFFT v7.017 (Katoh and Standley 2013), and GBlocks (Castresana 2000) was

159 used to remove poorly aligned, ambiguous nucleotide and gap positions in the $12 \mathrm{~S}$ and $16 \mathrm{~S}$

160 alignments. The coding genes were realigned and translated using TranslatorX (Abascal et al. 2010),

161 and an optimal partitioning scheme and nucleotide substitution models for a concatenated alignment

162 were determined using PartitionFinder v1.1.1 (Lanfear et al. 2012).

Previous molecular phylogenetic inferences have not recovered African bufonid species as

164 monophyletic (Graybeal 1997; Frost et al. 2006; Pramuk et al. 2008; Van Bocxlaer et al. 2010; Pyron

165 and Wiens 2011; Portik and Papenfuss 2015). To gain clarity on the phylogenetic relationship of

166 African species and to allow for geological time calibration, a 'global tree' inference was conducted

167 first. Along with African species, representatives of Eurasian and New World genera were included

168 in this inference, but only samples for which sequence data of all five gene regions was available

169 (with the exception of Incilius spp. and Bufotes surdus, included for calibration purposes despite

170 missing COI sequences). Although only 60 of the 101 currently recognized species are covered, all

171 African genera are represented in this tree, with the exception of Laurentophryne, a monotypic genus

172 from eastern Democratic Republic of the Congo that has not been sighted since its original collection

173 and description (Laurent 1950), despite recent efforts (Greenbaum and Kusamba 2012; IUCN SSC

174 Amphibian Specialist Group 2013). For the purpose of getting a more complete understanding of the

175 diversity of African lineages, a second alignment and phylogenetic reconstruction, restricted to

176 include only African species, was conducted, using sequence data for as many individuals as

177 possible, even if not all five genes were available. Due to the paraphyletic nature of African bufonids

178 (see results), this reconstruction excluded genera that were not part of the first African radiation

179 (FAR; applies to Central African genera: Nectophryne, Werneria and Wolterstorffina), because their 
180 inclusion would a) violate a number of assumptions related to monophyly and complete taxon

181 sampling for downstream analyses and b) an EO signal in diversification is not expected for

182 subsequent colonization events where the assumption of vacant niches no longer holds true (Schenk

183 et al. 2013). The resulting nucleotide matrix for this second inference favours taxon sampling

184 (covering 60 of the 89 currently recognized species of the FAR clade), but at the cost of missing

185 sequence data, fossil calibration points and species not belonging to the FAR clade.

186 Joint posterior distributions of all model parameters for both trees were estimated using

187 Bayesian Markov Chain Monte Carlo (MCMC) searches in BEAST v1.7.5 (Drummond et al. 2012a).

188 Molecular clock models were estimated for a linked set of the mitochondrial markers and for CXCR4

189 and RAG1 separately using uncorrelated lognormal relaxed clock (ucld) priors (Drummond et al.

190 2006) and birth-death tree prior (Gernhard 2008). The global tree was calibrated to geological units

191 of time by including four fossil node constraints: the estimated origin of the Rhinella marina species-

192 group (11.8 Ma; Estes and Wassersug 1963), the most recent common ancestor of Anaxyrus and

193 Incilius (20 Ma; Tihen 1951), the oldest unambiguously identified member of the Bufo bufo group

194 (9.6 Ma; Rage and Roček 2003) and the estimated age of the Bufotes viridis lineage (18 Ma; Martín

195 et al. 2012). As these fossils are not contained within the FAR clade, the crown age of the FAR tree

196 ingroup was calibrated using the crown age distribution of the FAR clade in the global tree. A total of

197 three MCMC searches with 100 million generations and three with 50 million generations, sampling

198 every $2000^{\text {th }}$ iteration, were conducted. For chain and parameter diagnostics, an additional MCMC

199 search on priors only was conducted, convergence and effective sample sizes (ESS) of parameters in

200 the log files as well as prior distributions were visually inspected using Tracer, and Are We There

201 Yet (AWTY; Wilgenbusch et al. 2004) was used to assess convergence of tree topologies. Posterior

202 trees were resampled and combined using LogCombiner v1.7.5 (Rambaut and Drummond 2012a)

203 and summarized as a maximum clade credibility (MCC) tree using TreeAnnotator v1.7.5 (Rambaut

204 and Drummond 2012b). 
Species Discovery

207 Two pruning methods were employed for deriving a tree with single representative tips per species.

208 First, the FAR phylogeny was pruned to include only a single representative per currently recognized

209 species (CRS; based on Frost 2016). However, extensive field and lab work by the authors and

210 collaborators has revealed a large number of undescribed species of African bufonids. Investigating

211 diversification rates using only currently recognized species is therefore not a true representation of

212 their phylogenetic diversity and to objectively obtain a tree that includes undescribed, but distinct,

213 taxa, the Bayesian implementation of the General Mixed Yule-Coalescent model (bGMYC; Pons et

214 al. 2006; Reid and Carstens 2012) was used to identify suitable delimitation points on the

215 chronogram to generate a second tree. Using the bGMYC package v1.0.2 (Reid 2014) in R (R core

216 team 2013), the algorithm was run for 1 million MCMC iterations, sampling every $10000^{\text {th }}$ iteration

217 after an initial 10000 repetition burn-in. Point estimates for species limits were derived using a 0.01

218 posterior probability cutoff threshold and the FAR MCC tree as well as a random subset of 1000

219 posterior trees were pruned to include only a single representative terminal per delimited element.

220 This pruning collapsed all divergences younger than 1.508 Ma resulting in an artificial flat-lining of

221 diversification. As this may not be biologically meaningful, all analyses were repeated on the

222 bGMYC tree with terminal branches truncated by 1.508 Myr (Supporting Information, Fig. S1.1e and

223 S7). The results did not differ substantially to those when using the bGMYC tree and are thus not

224 discussed further.

\section{Lineage Diversification}

227 Temporal and topological lineage diversification rate dynamics in the FAR clade (using both the

228 bGMYC and the CRS tree) were investigated in order to detect an early burst followed by a

229 slowdown in rate over time. The $\gamma$ statistic (Pybus and Harvey 2000) was calculated to test whether 
230 the net diversification of a given phylogeny departs from an exponential, pure-birth-like

231 accumulation of lineages using the ape package v3.2 (Paradis et al. 2004). To account for missing

232 taxa in the CRS tree, we employed a Monte Carlo Constant Rate (MCCR) test using the laser

233 package v 2.4-1 (Rabosky 2006).

234 Using a likelihood approach, we then compared two constant rate models (a pure-birth [PB]

235 and birth-death [BD] model with constant rates), to four variable rate models (PB with an exponential

236 speciation rate $[\mathrm{PB} \lambda \exp ], \mathrm{BD}$ with a constant speciation rate and exponential extinction rates

237 [BD $\lambda$ cst- $\mu$ exp], BD with an exponential speciation rate and constant extinction rate [BD $\lambda \exp -\mu c s t]$

238 and BD with both exponential speciation and extinction rates [BD $\lambda \exp -\mu \exp ])$, using the fit_bd

239 function of the RPANDA package v1.1 (Morlon et al. 2011, 2015). Model-fit was compared using

240 Akaike Information Criterion adjusted for small sample sizes (AICc) and Akaike weights (Aw).

241 Bayesian Analysis of Macroevolutionary Mixtures software (BAMM; Rabosky 2014) in

242 combination with the R package BAMMtools v.2.0 (Rabosky et al. 2014) was used to test whether

243 subclades diversify under distinct rate regimes. BAMM was allowed to sample every $1000^{\text {th }}$

244 generation of 5 million MCMC iterations, priors were configured based on the setBAMMprior

245 function in BAMMtools. The analysis using the bGMYC tree assumed complete sampling (see

246 extended methods; S1), whereas the analysis using the CRS tree was supplied with sampling

247 proportion information for each genus. For each analysis, four independent runs were executed to

248 check for convergence of the posterior probability densities, and Bayes factors were calculated to

249 compare the relative support of one rate regime model over another.

251 Life History Diversification

252 To explore how life history characters diversified over time, the rates of evolution and disparity of

253 body, clutch, and egg size were investigated. Mature female body size (snout-vent length in $\mathrm{mm}$ ),

254 clutch size (number of eggs per clutch), and egg size (diameter of eggs in $\mathrm{mm}$ ) were $\log 10$ 
255 transformed to better conform to normality and size-free residuals were subsequently calculated for

256 clutch and egg size data by regressing traits on body size using phylogenetic generalized least squares

257 (pGLS) regressions. Measurements were taken from Liedtke et al. (2014) and references therein, with

258 new measurements for Churamiti maridadi. Traits were mapped on the CRS tree and species for

259 which traits were unknown were pruned from the tree, resulting in a dataset of 60,46 and 42 species

260 for body, clutch, and egg size respectively.

261 A likelihood approach was used to compare the fit of a series of six evolutionary models to the

262 continuous trait data. Three constant rate models (Brownian motion [BM; Felsenstein 1973],

263 Ornstein-Uhlenbeck [OU; Butler and King 2004], and Pagel's lambda [Pagel 1999]) were compared

264 to three variable rate models (early-burst [EB; exponential rate change through time; Harmon et al.

265 2010], linear [LIN; linear rate change through time], and Pagel's time-dependent [Pagel 1999]

266 model). Models were fitted using the fitContinuous function of the geiger package v2.0 (Harmon et

267 al. 2008b) and comparisons were based on AIC and Aw. We further investigated the temporal rate

268 dynamics and rate heterogeneity of trait evolution using BAMM. For each trait, the rate shift

269 configuration with the highest posterior probability was determined and the rate profile through time

270 of the phenotypic rate parameter $\beta$ was plotted. In addition, the disparity of traits within and between

271 sub clades were investigated using the dtt function in the geiger package, and by calculating the

272 morphological disparity index (MDI; Harmon et al. 2003) to test for deviation from a Brownian

273 motion model.

274

275 Speciation Rates of Habitat Generalists versus Specialists

276 Species were scored as being either habitat generalists or habitat specialists based on the habitat

277 description provided by the IUCN red list database and the authors' first-hand experience

278 (www.iucnredlist.org; Table S1.3; Fig. 7). Our evaluation of habitat comprised of a two-step process:

279 (1) Constructing Table S1.3 based on IUCN data and checking for anomalies and/or mistakes. All 
280 authors participated in this process and have considerable experience working in the field

281 observing/collecting African amphibians, and (2) Filtering data according to evaluation from experts

282 and grouping according to being generalist (more than two distinct habitat types) or specialist (two or

283 less habitat types). It should be noted that certain habitat types were grouped giving the ambiguity in

284 the habitats being really distinct from one another. The Binary State Speciation and Extinction

285 (BiSSE) model implemented in the diversitree v.0.9-6 package (FitzJohn 2012) was used to examine

286 whether shifts in habitat specialization are associated with shifts in speciation rate using a maximum

287 likelihood (ML) and Bayesian approach (10000 iterations with 1000 iterations discarded as burn-in).

288 The analysis run with the CRS tree included sampling faction information to correct for biased

289 undersampling (sampling 0.72 of habitat generalists and 0.66 of habitat specialist) and the bGMYC

290 tree, coding undescribed species based on sampling locality and habitat preferences of their closest

291 relative. This method is known to be problematic when the number of terminals are low or when

292 character ratios are biased (Davis et al. 2013; Rabosky and Goldberg 2015), and so simulation tests

293 were performed (following Onstein et al. 2015) to ensure that there was sufficient power in the data

294 to avoid type I and type II errors (S1).

\section{Results}

297 Phylogenetic Inferences

298 The global tree (Fig. 1; Supporting Information S3) supports previous claims that African bufonids

299 are paraphyletic (Pramuk et al. 2008; Van Bocxlear et al. 2010; Portik et al. 2015), here recovering

300 two independent colonization events into Africa. Most relationships of Eurasian groups are poorly

301 resolved, but for both African radiations, internal nodes are generally well supported (posterior

302 probabilities $>0.9$ ). The global tree reconstruction dates the origin of the Old World radiation at 30.4

303 Ma (95\% Highest Posterior Density interval; HPD=23.2-38.5), with the two colonization events into

304 Africa occurring shortly after, at 29.4 Ma (95\% HPD=22.8-37.5) and 21.7 Ma (95\% HPD=15.8-29.4) 
respectively. An unexpectedly high degree of genetic divergences, especially within Nectophryne, Wolterstorffina, Nectophrynoides, Mertensophryne and in the Sclerophrys gracilipes-kisoloensisvilliersi complex were recovered, highlighting the need for taxonomic revisions of these groups. All major relationships were congruent in the global tree and the FAR tree (Supporting Information S3 and S4). When pruning the FAR tree to only include a single representative of each currently recognized species (CRS tree; Supporting Information S5), 60 out of the 89 known species are

311 represented with the missing 29 belonging to the following genera: Sclerophrys-15 (out of 38),

312 Mertensophryne-6 (out of 11), Nectophrynoides-2 (out of 15) and Poyntonophrynus-6 (out of 10).

\section{Species Discovery}

315 The bGMYC species discovery with a posterior probability threshold of 0.01 recovered 102

316 delimited entities (Supporting Information S4 and S6). Almost all currently recognized species of this

317 clade were delimited consistently, with the exception of three species pairs: Mertensophryne howelli

318 and M. usambarae, Poyntonophrynus damaranus and P. dombensis and Sclerophrys pardalis and $S$.

319 pantherinus, which were not identified as distinct entities. This echoes previous difficulties in

320 discerning the species status of at least the latter species pair (Poynton and Lambiris 1998; Measey

321 and Tolley 2009). In addition, units phylogenetically distinct from currently recognized species were

322 recovered in the following genera: Schismaderma-2, Nectophrynoides-13, Capensibufo-4,

323 Mertensophryne-8 and Sclerophrys-18. Cryptic diversity has previously been recognized (Poynton

324 and Broadley 1988; Tolley et al. 2010), and qualitative and quantitative assessments (acoustic calls,

325 distribution, genetics and morphology) of the entities recovered suggest that overall, delimited

326 elements are likely to represent valid species. We investigated the degree to which potential over-

327 splitting would affect our results by tracing the erosion of Pagel's $\gamma$ as delimited units are sequentially

328 dropped from the bGMYC tree to approach the CRS tree (supporting information S8). From this, we

329 can conclude that only if $\sim 58 \%$ or more of the delimited units are not true species, does Pagel's $\gamma$ 
330 deviate significantly from the below reported results. It is therefore unlikely that our estimation of

331 cryptic species is impacting the diversification results.

\section{Lineage Diversification}

334 Lineage through time plots for the bGMYC tree (102 terminals), the CRS tree (60 terminals) were

335 compared to a simulated set of 1000 pure-birth trees based on the total number of currently

336 recognized species (89 terminals; Fig. 2). For the bGMYC tree, a negative $\gamma$ was recovered, but the

337 relative distribution of splitting events was not significantly different from the null hypothesis of

338 constant rates through time $\left(\gamma_{\mathrm{MCC}}=-1.061, \mathrm{p}_{\mathrm{MCC}}=0.144 ;\right.$ mean $\left.\pm \mathrm{SD} \gamma_{\text {posterior }}=-0.951 \pm 0.537, \mathrm{p}=0.171\right)$.

339 Similarly, the observed $\gamma$ recovered for the CRS tree was negative $\left(\gamma_{\mathrm{MCC}}=-1.834\right.$; mean $\pm \mathrm{SD} \gamma_{\text {posterior }}=$ -

$3401.826 \pm 0.447$ ), but again was not significantly different from the null distribution (MCCR test $5 \%$

341 critical value $\left.=-2.449 ; \mathrm{p}_{\mathrm{MCC}}=0.158 ; \mathrm{p}_{\text {posterior }}=0.153\right)$.

342 For both trees (bGMYC and CRS tree), the best fitting models to describe lineage

343 diversification were constant rate, pure-birth models (Table 1). Fit over variable rate models was not

344 always substantial however. For the bGMYC tree, this model was a considerably better fit than any

345 variable rate model $(\mathrm{Aw}=0.501 ; \Delta \mathrm{AICc}>2.069$; Table 1$)$, but for the $\mathrm{CRS}$ tree, support for constant

346 diversification over variable rate models was less substantial ( $\mathrm{Aw}=0.452 ; \Delta \mathrm{AICc}>1.460 ;$ Table 1$)$.

347 For both the bGMYC and CRS tree, BAMM found strong support for rate homogeneity. A

348 model with a single evolutionary rate regime had the highest posterior probability $(\mathrm{PP}=0.650$ and

3490.630 for the two trees respectively; Fig. 3a) with posterior odds ratios of 2.390 (bGMYC) and 2.234

350 (CRS) and Bayes Factor scores of 1.624 (bGMYC) and 1.519 (CRS) over the next best models,

351 which in both cases were two-rate regime models (i.e. one rate shift). Support diminished with

352 complexity of the models (Fig. 3a). BAMM estimated extinction rates to be more or less constant

353 (and low) over time for both the bGMYC and CRS tree, with a slight increase in extinction rates in

354 recent history in the CRS tree (Fig. 3b). The CRS tree showed a marginal decline in speciation rate 
355 over time, whereas the bGMYC tree showed an initial increase followed by a flattening out of the

356 curve over time (Fig. 3b).

358 Life-history Diversification

359 Likelihood model fitting for rates of body, clutch, and egg size evolution, consistently recovered

360 constant rate models outperforming variable rate models (Table 2). For body and egg size, Pagel's $\lambda$

361 model performed best, but only for body size was this a noticeably better fit than the next best model

362 (body size $\mathrm{Aw}_{\lambda}=0.950$ over $\mathrm{Aw}_{\mathrm{OU}}=0.019$; egg size $\mathrm{Aw}_{\lambda}=0.280$ over $\mathrm{Aw}_{\mathrm{OU}}=0.226$; Table 2). For

363 clutch size, a Brownian motion model was the best fit $\left(\mathrm{Aw}_{\mathrm{BM}}=0.328\right.$ over the next best $\left.\mathrm{Aw}_{\lambda}=0.171\right)$.

364 Despite marginal differences in top model performances, the early burst model was consistently

365 ranked lowest for all three traits (body size $\mathrm{Aw}_{\mathrm{EB}}=0.003$; clutch size $\mathrm{Aw}_{\mathrm{EB}}=0.121$; egg size

$366 \mathrm{Aw}_{\mathrm{EB}}=0.042$ ). BAMM also recovered single-rate regimes as the best shift configurations for body,

367 clutch, and egg size although differences from more complex regime models were marginal

368 (posterior probabilities: $0.38 ; 0.53 ; 0.50$, Bayes factors: $1.29 ; 0.84 ; 0.84$ respectively). In line with the

369 likelihood model fitting, all three characters show relatively constant rates over time, with the

370 arguable exception of an initial increase in clutch size (Fig. 4).

371 The trait disparity analysis corroborates homogeneity in trait evolution. The average subclade

372 disparities of all three investigated life-history traits did not significantly deviate from expectation

373 under Brownian motion (MDI scores of $-0.022,-0.095$ and 0.077 for body, clutch, and egg size

374 respectively), but clutch size, and to some degree body size, show a more defined drop in subclade

375 disparity early on in the history of bufonids than expected (Fig. 5). The disparity plots for body size

376 and egg size indicate peaks during the last 5 million years, where disparity is greater than expected

377 under a BM model, which may be an artefact of under-sampling recent nodes (Harmon et al. 2003)

378 and unlikely to be a biological signal (see similar pattern in: Burbrink and Pyron 2009; Slater et al.

379 2010; Derryberry et al. 2011; Rowe et al. 2011). 
381 Speciation Rates of Habitat Generalists versus Specialists

382 Based on our coding, habitat specialists are more common than habitat generalists (bGMYC tree:

$38373 \%$, CRS tree: $83 \%$ ), but habitat generalists are present in all major subclades except in

384 Nectophrynoides. Both the ML and Bayesian approaches in BiSSE suggested a shift towards higher

385 speciation rates associated with shifts from habitat generalists to habitat specialists (Fig. 6). The ML

386 approach recovers the shift in speciation rates as significant when using the CRS tree (and

387 incorporating sampling fraction information), but not when using the bGMYC tree (CRS tree:

$388 \chi^{2}=4.779, \mathrm{p}=0.029 ; \mathrm{bGMYC}$ tree: $\left.\chi^{2}=0.508, \mathrm{p}=0.576\right)$. Transitions from generalist to specialists $(\mathrm{q} 01)$

389 were higher than vice versa (q10) for both the bGMYC (post burn-in MCMC medians: q01=0.060;

$390 \mathrm{q} 10=0.019)$ and the CRS tree (medians: $\mathrm{q} 01=0.113 ; \mathrm{q} 10=0.074)$.

\section{Discussion}

393 According to the EO model, expansion into new geographic areas should lead to a rapid

394 diversification both in lineages and in phenotypic traits. Once niches become saturated in the newly

395 colonized areas, rates should decrease in a diversity-dependent manner. Studies testing the EO model

396 have predominantly focused on young lineages restricted to small, isolated areas such as islands.

397 Whether the same niche filling principles can lead to bursts in biodiversity in continent-wide systems,

398 or if such burst can even be detected is less clear. By investigating the diversification history of one

399 of Africa's most species-rich amphibian colonizers, we tested whether signals characteristic of the

400 EO model can be recovered for this geographically and ecologically more complex, continental

401 system.

402

403

\section{Lineage and Trait Diversification of African Bufonids}


404 Key for accurately estimating diversification rates is the thorough sampling of species (Cusimano and

405 Renner 2010; Brock et al. 2011), which is difficult when dealing with a geographically expansive

406 radiation. Our extensive sampling and analyses of bufonids have revealed a sizable number of

407 undescribed species, up to 45 phylogenetically delimited units. These undescribed, mostly cryptic

408 lineages represent recent, species-level divergences and their exclusion from diversification analyses

409 creates an erroneous overestimation of early divergences relative to recent ones (Figs. 2, 3b;

410 Cusimano and Renner 2010). Critically, the inclusion of this cryptic diversity shows more apparently

411 that the lineage accumulation curve of African toads does not significantly differ from a simulated

412 constant rate curve (Pagels's $\gamma$ close to zero; Fig. 2) and that the diversification rate is best described

413 by a constant, pure-birth process (slightly outperforming a variable pure-birth process with a

414 marginally exponentially decreasing speciation rate over time; Table 1). Furthermore, there are no

415 significant rate regime shifts between subclades and thus, our data suggests that the first wave of

416 African bufonids as a whole, or any subclades therein, have not experienced a period of rapid lineage

417 expansion followed by a subsequent slowdown as expected under an EO mode (Fig. 3).

418 An early burst in diversification under the EO scenario would indicate the rapid filling of

419 available niches through adaptation and speciation. Analyses of trait evolution should reflect this in

420 the form of early partitioning of traits (Simpson 1953; Mahler et al. 2010), which has even been

421 suggested to be a more reliable signal for EO than lineage diversification (e.g. Slater et al. 2010;

422 Schweizer et al. 2014; but see Harmon et al. 2010). In African bufonids we find little deviation from

423 constant rates and subclade disparity through time in the evolution of life history traits (Table 2; Figs.

424 4, 5). At most, clutch size is partitioned more rapidly than expected, indicating that a division

425 between explosive and low-fecundity breeders likely occurred early on in the history of African

426 toads. However it should be noted that here too that deviation in trait evolution from expectations

427 under Brownian motion is not substantial. This is mirrored in the rate estimates over time that show a 428 steeper increase in rates closer to the root of the tree, but the overall rate change is minimal. Despite 
429 Simpson's predictions (Simpson 1953; shown also in more recent comparative studies e.g. Rabosky

430 et al. 2013), trait and lineage diversification need not always be coupled (Ruta et al. 2013) and

431 whether the constant lineage and trait diversification rates are correlated in bufonids requires further

432 testing. Nonetheless, the combined molecular and trait evidence from both analyses provides stronger

433 support for gradual evolutionary patterns on the continent of Africa - not an intuitively clear outcome

434 from previous studies and predictions (e.g. Van Bocxlaer et al. 2010).

435 High dispersal ability can facilitate geographic expansions while maintaining gene flow among

436 populations and thereby inhibit speciation (Claramunt et al. 2012a). Given the high-dispersal nature

437 of many bufonids (Van Bocxlaer et al. 2010), we predicted that the colonization of Africa by toads

438 need not result in the proliferation of ecological specialists, but instead can result in a lower number

439 of generalists. Based on our coding, the majority of species (at least $73 \%$ ) show narrow habitat

440 preferences and such specialists have experienced (albeit marginally) higher speciation rates than

441 their generalist counterparts (Fig. 6), a pattern frequently observed in other groups too (Hernández et

442 al. 2005 and references therein), and these specialists are most frequently derived from generalist

443 ancestors. We note such analyses are strongly subjected to the coding of traits, and determining

444 whether species are indeed habitat specialists is not trivial and our analysis provides only the first

445 assessment of this. Nonethless, the BAMM analysis places the highest probability for rate shifts to

446 have occurred along the basal branches of Nectophrynoides (data not shown), a highly specialized

447 genus restricted to montane environments (Müller and Liedtke et al. 2013) and the largest subclade

448 with no habitat generalists. Because generalist lineages have persisted in most other subclades of

449 African bufonids they may have contributed to a buffering of the explosive early niche-filling that is

450 central to the EO model. However, we caution against an over interpretation of this finding, as

451 differences in speciation rates between generalists and specialists were marginal, and the overall

452 number of generalist species was comparatively low. Nonetheless, a similar scenario has been 
453 proposed for furnariid birds of South America (Claramunt et al. 2012a,b) and the exceptional ability

454 of some organisms to colonize large areas may ultimately inhibit their lineage proliferation.

456 Is the EO Model a Good Framework for explaining Diversification in Colonizers of Continental

457 Systems?

458 A growing number of studies on a diverse range of vertebrates have failed to find evidence for

459 diversity-dependent rate curves (Neotropical birds: Derryberry et al. 2011; Claramunt et al. 2012b;

460 Schweizer et al. 2014; African catfish: Day et al. 2013; murid rodents: Schenk et al. 2013). A trend is

461 seemingly emerging that EO, frequently considered a precursor for generating diversity in insular

462 systems (Arbogast et al. 2006; Hughes and Eastwood 2006; Harmon et al. 2008a; Jønsson et al. 2012;

463 but see Esselstyn et al. 2009; Losos and Mahler 2010) may not always be an appropriate model for

464 explaining diversification patterns in continent-wide radiations. Here, we discuss, using our data on

465 toads, possible reasons why constant diversification rates may indeed be more common for

466 continental systems and why some studies continue to find EO signals. Reasons why EO might

467 simply not be detectable are discussed in the ensuing sections.

468 Tabula Rasa? - Most African amphibian families are endemic and relatively old (Andreone et

469 al. 2008), with molecular (Cannatella and de Sá 1993; Duellman 1993; Vences et al. 2003; Van

470 Bocxlaer et al. 2006; Roelants et al. 2007; Barej et al. 2014) and fossil (Duellman 1999; Blackburn et

471 al. 2015; Gardner and Rage 2016) data suggesting that there is a long history of amphibian

472 assemblages on the continent. Bufonids were late arrivers on the continent of Africa and may not

473 have been presented with the opportunity of 'vacant' niches. Furthermore, competition for resources

474 need not be restricted to interactions only with other amphibians; macroinvertebrates for example,

475 directly compete for resources with tadpoles (Morin et al. 1988). Schenk et al. (2013), comparing

476 successive colonization events in rodents, have shown that indeed, secondary lineages, on average,

477 diversify to a lesser extent regardless of whether or not primary colonizers exhibit early burst 
478 diversification patterns. In our system too, the second African toad radiation (although not treated in

479 detail here) appears to be much less diverse than the first, despite comparable clade ages (12, relative

480 to 89 recognized species resulting in 0.553 compared to 3.027 species per million years respectively,

481 when dividing number of extant species by clade age). The concept of 'vacant' niches may therefore

482 be unrealistic for continental systems that tend to have much older histories of supporting life than

483 unbalanced assemblages in insular systems. Only in cases where a specific 'ecomorph' is

484 underrepresented may colonizers continue to be truly presented with EO on continental systems (e.g.

485 Burbrink and Pyron 2009).

486 Scale and complexity.-The ecological limits for diversity may not easily be reached if an area

487 is large (Kisel et al. 2011) and dispersal ability of organisms is high (Fritz et al. 2011). Continents

488 tend to be larger than insular systems, and high dispersal ability would be important for successful,

489 continent-wide colonisation. With an area of approximately 30 million $\mathrm{km}^{2}$, the potential carrying

490 capacity of Africa dictated by the species-area relationship alone (MacArthur and Wilson 1967;

491 Lomolino 2000) is exceedingly high and it seems plausible that a saturation point of resources,

492 causing a diversity dependent decline in diversification, may never be reached by toads, or at least

493 has not been reached yet, as has been speculated for African catfish (Day et al. 2013).

494 The dynamic geographic changes that impact the history of life are likely to produce highly

495 complex conditions for diversification of lineages under the assumptions of an EO model. For

496 example, the successive rising of new islands in Southeast Asia is thought to have produced repeated

497 EO for shrews to diversify, contra to expectations sustaining a constant diversification rate, instead of 498 reaching the expected diversity-dependent slowdown (Esselstyn et al. 2009). Since the Oligocene,

499 Africa has experienced a fluctuating climate (Richards 1973; Flenley 1979; Livingstone 1993;

500 Parmentier et al. 2007) and one can imagine that the resulting expansion and contraction of habitats

501 and species ranges (Nakazawa and Peterson 2015) could equally have resulted in a pattern of

502 repeated regional opportunity, concealing any singular continent-wide EO signal. Geographic range 
503 expansions into the Andes for example has been attributed to promoting repeated bursts of

504 diversification within continent-wide radiations of legumes (Drummond et al. 2012b) and

505 hummingbirds (McGuire et al. 2014). In line with the notion of continuous opportunity, the slow

506 decline of competing lineages (as seen in Quental and Marshall 2013) may have similarly presented

507 bufonids with gradual niche-filling opportunities over its entire history, not just immediately after its 508 colonization of Africa.

509 Broad habitat tolerance limits EO diversification.- Habitat generalists are likely to be less

510 hindered by ecological barriers to dispersal, which is an important trait for successful long distance

511 dispersal and colonization (Baur and Bengtsson 1987; Van Bocxlaer et al. 2010; Dennis et al. 2012).

512 This dispersal ability of habitat generalists would however, potentially limit genetic isolation caused

513 by geographic fragmentation through fluctuating ecological conditions or geographic barriers,

514 resulting in lower diversification than in specialists (Price and Wagner 2004; Phillimore et al. 2006;

515 Von Rintelen et al. 2010; Claramunt et al. 2012a; Salisbury et al. 2012; but see Moyle et al. 2009).

516 Therefore, an alternative to an explosive, niche-filling diversification history resulting in large

517 numbers of habitat specialists as predicted by the EO model may be a diversification history

518 dominated by less explosive, habitat generalist lineages.

520 Caveats

521 Based on rates of evolution in traits and lineages our data suggest bufonids did not experience an

522 early burst followed by a diversity dependent slowdown. Simpson (1953) pointed out that

523 opportunity alone may not be sufficient to promote invasion of new ecological space. As Simpson

524 outlined, if an evolutionary lineage is constrained or unable to 'take advantage' of evolutionary

525 opportunities (Simpson 1953; Schluter 2000) some radiations may simply fail to be explosive if the

526 necessary traits do not exist/evolve (Steelman and Danley 2003; Losos 2010; Yoder et al. 2010).

527 Studies on the selective pressures acting on toads and competition with other species are required to 
528 better evaluate potential constraints on EO, and whether such factors form the basis for explaining 529 non-EO evolutionary patterns.

530 Alternatively, EO may indeed have been presented to bufonids upon colonizing Africa, but we

531 have failed to detect it. Diversification rate estimates require a number of assumptions concerning

532 estimates of speciation and extinction, which question the veracity of interpreting diversification

533 patterns outlined in this study. For example, high rates of extinction can erode signals of early bursts

534 in phylogenies (Rabosky and Lovette 2008b). Although we included models that fit varying

535 extinction rates through time, estimating this parameter from molecular phylogenies is problematic

536 (Rabosky 2009b) and both $\gamma$ and the MCCR test are known to be conservative with respect to

537 extinction, and produce high type II errors (Pybus and Harvey 2000; Brock et al. 2011). If extinction

538 rates were indeed low (as estimated by our analyses), but sufficient time has elapsed since the

539 equilibrium diversity has been reached, traces of initial diversity-dependent lineage accumulation

540 may again be lost (Liow et al. 2010; Rabsky and Hurlbert 2015). With a limited fossil record for

541 African bufonids, direct evidence for estimating extinction rates is lacking, but Raven and Axelrod

542 (1974) suggested that angiosperms in Africa have experienced high extinction rates during the

543 Tertiary and Quaternary, a history that if shaped by climate, might have been similar for amphibians.

\section{Conclusion}

546 Bufonids are renowned as one of the few amphibian radiations that have achieved a near global

547 distribution, with peaks in diversification rates during dispersal periods to new continents facilitated

548 by the evolution of the 'toad-like' phenotype. Yet despite impressive present-day diversity, upon

549 arriving in Africa, lineage and trait diversification rates appear to have been constant over time,

550 showing no early burst signal as might be expected under an EO model. Based on the findings

551 presented here and recent studies in other groups, we conclude that constant-rate and trait

552 diversification might be the more pervasive model for continent-scale radiations in general. The 
553 constant overall rate might be due to more complex geographic and climatic histories of continents

554 coupled with lineage specific traits, such as those promoting habitat generalism, which might buffer

555 against rapid EO-driven diversification. Limitations of current methods to detect early burst signals

556 for old radiations and a depauperate fossil record makes an adequate evaluation of these factors

557 difficult at this point, but our initial investigations into the role habitat generalism may have in

558 buffering speciation is encouraging for further investigations into understanding how habitat

559 tolerance affects large scale colonization success and diversification rates.

561 Acknowledgments

562 We would like to thank the following people and institutes for providing logistical support and/or

563 facilitating the loans of tissue samples: Andy Plumptre (WCS); Bryan Stuart (NCSM); Jose Rosado,

564 Breda Zimkus, and Joanna Larson (MCZ); Carol Spencer and Daniel Portik (MVZ); David Gower,

565 Mark Wilkinson, John Poynton, and Barry Clark (NHM); Ines Van Bocxlaer and Franky Bossuyt

566 (VUB); Gabriela Bittencourt (University of Basel); Jean Mariaux (MHN); Kim Howell (UDSM);

567 Krystal Tolley and Zoe Davids (SANBI); Laura Sandberger, Mareike Hirschfeld, and Frank Tillack

568 (ZMB); Les Minter and Louis Du Preez (NWU); Patrick Malonza, Victor Wasonga, and Beryl

569 Bwong (NMK); Raffael de Sá (University of Richmond); Rayna Bell (Cornell University); Jens

570 Vindum, Robert Drewes, and David Blackburn (CAS); Alan Resetar and William Stanley (FMNH);

571 Wolfgang Böhme and Dennis Rödder (ZFMK); and Beatriz Alvarez Dorda (MNCN). We would also

572 like to thank Reto Hagmann and Maiti Laserna de Himpsl for their help with lab work, Sara

573 Ceccarelli, Renske Onstein, and Karen Siu-Ting for constructive discussions on methods and for

574 providing code, Martin Jacquot for his assistance with the high performance cluster, Anastasios

575 Noulas for a useful python script and James Cotton and Julia Day for comments on the manuscript. 
578 This work was supported by the Swiss National Science Foundation (grant number 31003A-133067

579 to S.P.L. and P2BSP3_158846 to H.C.L.) and by the Freiwillige Akademische Gesellschaft Basel.

580 V.G. was supported by the Czech Science Foundation (GACR, project number 15-13415Y), and IVB

581 institutional support (RVO: 68081766).

582

583 References

584 Abascal, F., R. Zardoya, and M. J. Telford. 2010. TranslatorX: multiple alignment of nucleotide sequences guided by amino acid translations. Nucleic Acids Res. 38:1-7.

Alhajeri, B. H., J. J. Schenk, and S. J. Steppan. 2015. Ecomorphological diversification following continental colonization in muroid rodents (Rodentia: Muroidea). Biol. J. Linn. Soc. 117:463481 .

Andreone, F., A. Channing, R. C. Drewes, J. Gerlach, F. Glaw, K. M. Howell, M. Largen, S. P. Loader, S. Lötters, L. R. Minter, M. Pickersgill, C. Raxworthy, M.-O. Rödel, A. Schiøtz, D. Vallan, and M. Vences. 2008. Amphibians of the Afrotropical realm. Pp. 53-64 in Threatened

Arbogast, B. S., S. V. Drovetski, R. L. Curry, P. T. Boag, G. Seutin, P. R. Grant, B. R. Grant, and D. Amphibians of the World. Lynx Edicions, Barcelona.

Barej, M. F., A. Schmitz, R. Günther, S. P. Loader, K. Mahlow, and M.-O. Rödel. 2014. The first endemic West African vertebrate family - a new anuran family highlighting the uniqueness of the Upper Guinean biodiversity hotspot. Front. Zool. 11:8.

599 Barker, F. K., K. J. Burns, J. Klicka, S. M. Lanyon, and I. J. Lovette. 2013. Going to extremes:

600 contrasting rates of diversification in a recent radiation of New World passerine birds. Syst.

$601 \quad$ Biol. 62:298-320. 
602 Baur, B. and J. Bengtsson, J. 1987. Colonizing ability in land snails on Baltic uplift archipelagos. J. Biogeogr. 14:329-341.

604 Blackburn, D. C., E. M. Roberts and N. J. Stevens. 2015. The earliest record of the endemic African frog family Ptychadenidae from the Oligocene Nsungwe Formation of Tanzania. J. Vertebr. Paleontol. 35:e907174-6.

Blair, W. F. 1972. Evolution in the Genus Bufo. 1st ed. University of Texas Press, Texas.

Brock, C. D., Harmon, L. J. and M. E. Alfaro. 2011. Testing for temporal variation in diversification rates when sampling is incomplete and nonrandom. Syst. Biol. 60:410-419.

Burbrink, F. T., and R. A. Pyron. 2009. How does ecological opportunity influence rates of speciation, extinction, and morphological diversification in new world ratsnakes (tribe Lampropeltini)? Evolution 64:934-943.

Butler, M. A., and A. A. King. 2004. Phylogenetic comparative analysis: a modeling approach for adaptive evolution. Am. Nat. 164:683-695.

Cannatella, D. C., and R. O. de Sá. 1993. Xenopus laevis as a model organism. Syst. Biol. 42:476507.

Castresana, J. 2000. Selection of conserved blocks from multiple alignments for their use in phylogenetic analysis. Mol. Biol. Evol. 17:540-552.

Claramunt, S., E. P. Derryberry, J. V. Remsen, and R. T. Brumfield. 2012a. High dispersal ability inhibits speciation in a continental radiation of passerine birds. P. Roy. Soc. B-Biol. Sci. 279:1567-1574.

Claramunt, S., E. P. Derryberry, R. T. Brumfield, and J. V. Remsen Jr. 2012b. Ecological opportunity and diversification in a continental radiation of birds: climbing adaptations and cladogenesis in the Furnariidae. Am. Nat. 179:649-666.

Clarke, B. T. 2001. Towards a natural classification of African toads (Anura, Bufonidae): Past progress and future prospects. Afr. J. Herpetol. 50:19-30. 
627 Cusimano, N., and S. S. Renner. 2010. Slowdowns in diversification rates from real phylogenies may

628 not be real. Syst. Biol. 59:458-464.

629 Davis, M. P., P. E. Midford, and W. Maddison. 2013. Exploring power and parameter estimation of 630 the BiSSE method for analyzing species diversification. BMC Evol. Biol. 13:38.

631 Davis, W. B. 1938. Relation of size of pocket gophers to soil and altitude. J. Mammal. 19:338-342.

632 Day, J. J., C. R. Peart, K. J. Brown, J. P. Friel, R. Bills, and T. Moritz. 2013. Continental diversification of an African catfish radiation (Mochokidae: Synodontis). Syst. Biol. 62:351365.

Dennis, R. L. H., P. B. Hardy and L. Dapporto. 2012. Nestedness in island faunas: novel insights into island biogeography through butterfly community profiles of colonization ability and migration capacity. J. Biogeogr. 39:1412-1426.

Derryberry, E. P., S. Claramunt, G. Derryberry, R. T. Chesser, J. Cracraft, A. Aleixo, J. Pérez-Emán, evolution in a large-scale continental radiation: the neotropical ovenbirds and woodcreepers (Aves: Furnariidae). Evolution 65:2973-2986.

Dobzhansky, T. 1950. Evolution in the tropics. Am. Sci. 38:209-221.

Drummond, A. J., M. A. Suchard, D. Xie, and A. Rambaut. 2012a. Bayesian phylogenetics with BEAUti and the BEAST 1.7. Mol. Biol. Evol. 29:1969-1973.

Drummond, A. J., S. Y. W. Ho, M. J. Phillips, and A. Rambaut. 2006. Relaxed phylogenetics and dating with confidence. PLoS Biol. 4:e88.

Drummond, C. S., R. J. Eastwood, S. T. S. Miotto, and C. E. Hughes. 2012b. Multiple continental radiations and correlates of diversification in Lupinus (Leguminosae): testing for key innovation with incomplete taxon sampling. Syst. Biol. 61:443-460.

Duellman, W. E. 1993. Amphibians in Africa and South America: evolutionary history and ecological comparisons. Pp. 200-243 in P. Goldblatt, ed. Biological relationships between 
Africa and South America. Yale University Press, New Haven and London.

653 Duellman, W. E. 1999. Patterns of distribution of amphibians: a global perspective. JHU Press, $654 \quad$ Baltimore.

655 Duellman, W. E., and L. Trueb. 1994. Biology of amphibians. Johns Hopkins University Press, $656 \quad$ Baltimore.

657 Esselstyn, J. A., R. M. Timm, and R. M. Brown. 2009. Do geological or climatic processes drive speciation in dynamic archipelagos? The tempo and mode of diversification in Southeast Asian shrews. Evolution 63:2595-2610.

660 Estes, R., and R. J. Wassersug. 1963. A Miocene toad from Colombia, South America. Breviora. 193:1-13.

662 Felsenstein, J. 1973. Maximum-likelihood estimation of evolutionary trees from continuous characters. Am. J. Hum. Genet. 25:471-492.

664 FitzJohn, R. G. 2012. Diversitree: comparative phylogenetic analyses of diversification in R. Methods Ecol. Evol. 3:1084-1092.

666 Flenley, J. 1979. The equatorial rain forest: a geological history. Butterworths, London.

667 Fritz, S. A., K. A. Jønsson, J. Fjeldså, and C. Rahbek. 2011. Diversification and biogeographic 668 patterns in four island radiations of passerine birds. Evolution 66:179-190.

669 Frost, D. R. 2016. Amphibian Species of the World: an Online Reference. Version 6.0. Electronic 670 Database accessible at http://researchamnhorg/herpetology/amphibia/indexhtml. American 671 Museum of Natural History, New York, USA. (last accessed 25 February 2016).

672 Frost, D. R., T. Grant, J. Faivovich, R. H. Bain, A. Haas, C. F. B. Haddad, R. O. De Sa, A. Channing, M. Wilkinson, and S. C. Donnellan. 2006. The amphibian tree of life. B. Am. Mus. Nat. Hist.

675 Gardner, J.D. and J.-C. Rage. 2016. The fossil record of lissamphibians from Africa, Madagascar, 676 and the Arabian Plate. Palaeobio. Palaeoenv. 2016:1-52. 
677 Gernhard, T. 2008. The conditioned reconstructed process. J. Theor. Biol. 253:769-778.

678 Grant, P. R. 1999. Ecology and evolution of Darwin's finches. pp 512. Princeton University Press, 679 Princeton, NJ.

680 Graybeal, A. 1997. Phylogenetic relationships of bufonid frogs and tests of alternate macroevolutionary hypotheses characterizing their radiation. Zool. J. Linn. Soc. Lond. 119:297-338.

Greenbaum, E., and C. Kusamba. 2012. Conservation implications following the rediscovery of four frog species from the Itombwe Natural Reserve, eastern Democratic Republic of the Congo. Herpetol. Rev. 43:253-259.

Harmon, L. J., and S. Harrison. 2015. Species diversity is dynamic and unbounded at local and continental scales*. Am. Nat. 185:584-593.

Harmon, L. J., J. A. Schulte, A. Larson, and J. B. Losos. 2003. Tempo and mode of evolutionary radiation in iguanian lizards. Science 301:961-964.

Harmon, L. J., J. B. Losos, T. Jonathan Davies, R. G. Gillespie, J. L. Gittleman, W. Bryan Jennings,

$$
\text { K. H. Kozak, M. A. McPeek, F. Moreno-Roark, T. J. Near, A. Purvis, R. E. Ricklefs, D. }
$$
Schluter, J. A. Schulte II, O. Seehausen, B. L. Sidlauskas, O. Torres-Carvajal, J. T. Weir, and

Harmon, L., J. Melville, A. Larson, and J. B. Losos. 2008a, The role of geography and ecological opportunity in the diversification of day geckos (Phelsuma). Syst. Biol. 57:562-573. investigating evolutionary radiations. Bioinformatics 24:129-131. specialization: testing the resource-use hypothesis. Evol. Ecol. 19:199-219.

Hughes, C., and R. Eastwood. 2006. Island radiation on a continental scale: Exceptional rates of plant 
diversification after uplift of the Andes. P. Natl. Acad. Sci. USA 103:10334-10339.

703

704

705

706

707

708

709

710

711

712

713

714

715

716

717

718

719

720

721

722

723

724

725

726

Hunter, J. P., and J. Jernvall. 1995. The hypocone as a key innovation in mammalian evolution. P. Natl. Acad. Sci. USA 92:10718-10722.

IUCN SSC Amphibian Specialist Group 2013. n.d. Laurentophryne parkeri. in IUCN 2013. IUCN Red List of Threatened Species. Version 2013.2. www.iucnredlist.org. (last accessed on 6 January 2014).

Jønsson, K. A., P.-H. Fabre, S. A. Fritz, R. S. Etienne, R. E. Ricklefs, T. B. Jørgensen, J. Fjeldså, C. Rahbek, P. G. P. Ericson, F. Woog, E. Pasquet, and M. Irestedt. 2012. Ecological and evolutionary determinants for the adaptive radiation of the Madagascan vangas. P. Natl. Acad. Sci. USA 109:6620-6625.

Katoh, K., and D. M. Standley. 2013. MAFFT multiple sequence alignment software version 7: improvements in performance and usability. Mol. Biol. Evol. 30:772-780.

Kearse, M., R. Moir, A. Wilson, S. Stones-Havas, M. Cheung, S. Sturrock, S. Buxton, A. Cooper, S. Markowitz, C. Duran, T. Thierer, B. Ashton, P. Meintjes, and A. Drummond. 2012. Geneious Basic: An integrated and extendable desktop software platform for the organization and analysis of sequence data. Bioinformatics 28:1647-1649.

Kisel, Y., L. McInnes, N. H. Toomey, and C. D. L. Orme. 2011. How diversification rates and diversity limits combine to create large-scale species-area relationships. Philos. T. Roy. Soc. B $366: 2514-2525$.

Kozak, K. H., and J. J. Wiens. 2006. Does niche conservatism promote speciation? A case study in North American salamanders. Evolution 60:2604-2621.

Lanfear, R., B. Calcott, S. Y. W. Ho, and S. Guindon. 2012. PartitionFinder: combined selection of partitioning schemes and substitution models for phylogenetic analyses. Mol. Biol. Evol. 29:1695-1701.

Laurent, R. F. 1950. Diagnoses préliminaires de treize batraciens nouveaux d'Afrique centrale. Rev. 
Zool. Bot. Afr. 44:1-18.

728 Liedtke, H. C. 2014. The evolution of terrestrial breeding in African amphibians (PhD Thesis).

$729 \quad$ University of Basel.

730 Liedtke, H. C., H. Müller, J. Hafner, P. Nagel, and S. P. Loader. 2014. Interspecific patterns for egg 731 and clutch sizes of African Bufonidae (Amphibia: Anura). Zool. Anz. 253:309-315.

732 Liow, L.H., T. B. Quental and C. R. Marshall. 2010. When can decreasing diversification rates be 733 detected with molecular phylogenies and the fossil record? Syst. Biol. 59:646-659.

734 Livingstone, D. A. 1993. Evolution of African climate. Pp. 456-472 in P. Goldblatt, ed. Biological 735 relationships between Africa and South America. Yale University Press, New Haven and $736 \quad$ London.

737 Lomolino, M. V. 2000. Ecology's most general, yet protean pattern: the species-area relationship. J. $738 \quad$ Biogeogr. 27:17-26.

739 Losos, J. B. 2010. Adaptive radiation, ecological opportunity, and evolutionary determinism. Am. $740 \quad$ Nat. 175:623-639.

741 Losos, J. B., and D. L. Mahler. 2010. Adaptive Radiation: the Interaction of Ecological Opportunity, 742 Adaptation, and Speciation. Pp. 381-420 in M. Bell, D. J. Futuyma, W. F. Eanes, and J. S.

744 MacArthur, R. H., and E. O. Wilson. 1967. The theory of island biogeography. Princeton University $745 \quad$ Press, Princeton, NJ.

746 Mahler, D. L., L. J. Revell, R. E. Glor, and J. B. Losos. 2010. Ecological opportunity and the rate of 747 morphological evolution in the diversification of Greater Antillean anoles. Evolution 64:2731$748 \quad 2745$.

749 Martín, C., M. A. Alonso-Zarazaga, and B. Sanchiz. 2012. Nomenclatural notes on living and fossil 750 amphibians. Graellsia 68:159-180.

751 McGuire, J. A., C. C. Witt, J. V. Remsen Jr, A. Corl, D. L. Rabosky, D. L. Altshuler, and R. Dudley. Page 31 of 42 

2014. Molecular phylogenetics and the diversification of hummingbirds. Curr. Biol. 24:910916.

754

755

756

757

758

759

760

761

762

763

764

765

766

767

768

769

770

771

772

773

774

775

776

McKenna, D. D., A. S. Sequeira, A. E. Marvaldi, and B. D. Farrell. 2009. Temporal lags and overlap in the diversification of weevils and flowering plants. P. Natl. Acad. Sci. USA 106:7083-7088.

Measey, G. J., and K. A. Tolley. 2009. Investigating the cause of the disjunct distribution of Amietophrynus pantherinus, the Endangered South African western leopard toad. Conserv. Genet. 12:61-70.

Mooers, A. O., and S. B. Heard. 1997. Inferring evolutionary process from phylogenetic tree shape. Q. Rev. Biol. 72:31-54.

Morin, P. J., S. P. Lawler, and E. A. Johnson. 1988. Competition between aquatic insects and vertebrates: interaction strength and higher order interactions. Ecology 69:1401-1409.

Morlon, H., E. Lewitus, F. L, Condamine, M. Manceau, J. Clavel and J. Drury. 2016. RPANDA: an R package for macroevolutionary analyses on phylogenetic trees. Method. Ecol. Evol. doi:10.1111/2041-210X.12526.

Morlon, H., T. L. Parsons, and J. B. Plotkin. 2011. Reconciling molecular phylogenies with the fossil record. P. Natl. Acad. Sci. USA 108:16327-16332.

Moyle, R. G., C. E. Filardi, C. E. Smith and J. Diamond. 2009. Explosive Pleistocene diversification and hemispheric expansion of a "great speciator". P. Natl. Acad. Sci. USA 106:1863-1868.

Müller, H., H. C. Liedtke, M. Menegon, J. Beck, L. Ballesteros-Mejia, P. Nagel and S. P. Loader. 2013. Forests as promoters of terrestrial life-history strategies in East African amphibians. Biol. Lett. 9:20121146-20121146.

Nakazawa, Y., and A. T. Peterson. 2015. Effects of climate history and environmental grain on species' distributions in Africa and South America. Biotropica 47:292-299.

Nee, S., A. O. Mooers, and P. H. Harvey. 1992. Tempo and mode of evolution revealed from molecular phylogenies. P. Natl. Acad. Sci. USA 89:8322-8326. 
777 Onstein, R. E., R. J. Carter, Y. Xing, J. E. Richardson, and H. P. Linder. 2015. Do Mediterranean-

778 type ecosystems have a common history?-Insights from the Buckthorn family (Rhamnaceae).

$779 \quad$ Evolution 69:756-771.

780 Pagel, M. 1999. Inferring the historical patterns of biological evolution. Nature 401:877-884.

781 Paradis, E., J. Claude, and K. Strimmer. 2004. APE: Analyses of Phylogenetics and Evolution in R 782 language. Bioinformatics 20:289-290.

783 Parmentier, I., Y. Malhi, B. Senterre, R. J. Whittaker, A. T. D. N, A. Alonso, M. P. B. Balinga, A. Bakayoko, F. Bongers, C. Chatelain, J. A. Comiskey, R. Cortay, M.-N. D. Kamdem, J.-L. Doucet, L. Gautier, W. D. Hawthorne, Y. A. Issembe, F. N. Kouamé, L. A. Kouka, M. E. Leal, J. Lejoly, S. L. Lewis, L. Nusbaumer, M. P. E. Parren, K. S. H. Peh, O. L. Phillips, D. Shell, B. Sonké, M. S. M. Sosef, T. C. H. Sunderland, J. Stropp, H. Ter Steege, M. D. Swaine, M. G. P.

Peters, R. H. 1986. The ecological implications of body size. Cambridge University Press, Tchouto, B. S. Van Gemerden, J. L. C. H. Van Valkenburg, and A. H. Wöll. 2007. The odd man out? Might climate explain the lower tree $\alpha$-diversity of african rain forests relative to amazonian rain forests? J. Ecol. 95:1058-1071.

Phillimore, A. B., R. P. Freckleton, C.D. L. Orme and I. P. F. Owens. 2006. Ecology predicts large Cambridge. scale patterns of phylogenetic diversification in birds. Am. Nat. 168:220-229.

Pinto, G., D. L. Mahler, L. J. Harmon, and J. B. Losos. 2008. Testing the island effect in adaptive

Pons, J., T. G. Barraclough, J. Gomez-Zurita, A. Cardoso, D. Duran, S. Hazell, S. Kamoun, W. undescribed insects. Syst. Biol. 55:595-609.

801 Portik, D.M. and T. J. Papenfuss. 2015. Historical biogeography resolves the origins of endemic 
802

803

804

805

806

807

808

809

810

811

812

813

814

815

816

817

818

819

820

821

822

823

824

825

826

Arabian toad lineages (Anura: Bufonidae): Evidence for ancient vicariance and dispersal events with the Horn of Africa and South Asia. BMC Evol. Biol. 15:1-19.

Poynton, J. C. 1997. On Bufo nyikae Loveridge and the B. lonnbergi complex of East African highlands (Anura: Bufonidae). Afr. J. Herpetol. 46:98-102.

Poynton, J. C., and A. J. L. Lambiris. 1998. On Bufo pantherinus A. Smith, 1828 (Anura:

Bufonidae), the leopard toad of the southwestern Cape, South Africa, with the designation of a neotype. Afr. J. Herpetol. 47:3-12.

Poynton, J. C., and D. G. Broadley. 1988. Amphibia Zambesiaca 4. Bufonidae. Ann. Natal Mus. 29:447-490.

Pramuk, J. B., T. Robertson, J. W. Sites, and B. P. Noonan. 2008. Around the world in 10 million years: biogeography of the nearly cosmopolitan true toads (Anura: Bufonidae). Global Ecol. Biogeogr. 17:72-83.

Price, J.P. and W. L. Wagner. 2004. Speciation in Hawaiian angiosperm lineages: cause, consequence, and mode. Evolution 58:2185-17.

Price, S. L., S. Powell, D. J. C. Kronauer, L. A. P. Tran, N. E. Pierce, and R. K. Wayne. 2014a. Renewed diversification is associated with new ecological opportunity in the Neotropical turtle ants. J. Evolution. Biol. 27:242-258.

Price, T. D., D. M. Hooper, C. D. Buchanan, U. S. Johansson, D. T. Tietze, P. Alström, U. Olsson, M. Ghosh-Harihar, F. Ishtiaq, S. K. Gupta, J. Martens, B. Harr, P. Singh, and D. Mohan. 2014b. Niche filling slows the diversification of Himalayan songbirds. Nature 509:222-225.

Pybus, O. G., and P. H. Harvey. 2000. Testing macro-evolutionary models using incomplete molecular phylogenies. P. Roy. Soc. B-Biol. Sci. 267:2267-2272.

Pyron, R. A., and J. J. Wiens. 2011. A large-scale phylogeny of Amphibia including over 2800 species, and a revised classification of extant frogs, salamanders, and caecilians. Mol. Phylogenet. Evol. 61:543-583. 
827 Quental, T.B. and C.R. Marshall. 2013. How the Red Queen drives terrestrial mammals to extinction. Science, 341: 290-292.

829 R core team. 2013. R: a language and environment for statistical computing. R Foundation for $830 \quad$ Statistical Computing, Vienna, Austria, http://www.R-project.org/.

831 Rabosky, D.L. 2006. LASER: a maximum likelihood toolkit for detecting temporal shifts in 832 diversification rates from molecular phylogenies. Evol. Bioinform. 2:247-250.

833 Rabosky, D. L. 2014. Automatic detection of key innovations, rate shifts, and diversity-dependence $834 \quad$ on phylogenetic trees. PLoS ONE 9:e89543.

835 Rabosky, D. L. 2009a. Ecological limits and diversification rate: alternative paradigms to explain the 836 variation in species richness among clades and regions. Ecol. Lett. 12:735-743.

837 Rabosky, D. L. 2009b. Extinction rates should not be estimated from molecular phylogenies. $838 \quad$ Evolution 64:1816-1824.

839 Rabosky, D. L., and A. H. Hurlbert. 2015. Species richness at continental scales is dominated by $840 \quad$ ecological limits*. Am. Nat. 185:572-583.

841 Rabosky, D. L., and E. E. Goldberg. 2015. Model inadequacy and mistaken inferences of trait842 dependent speciation. Syst. Biol. 64:340-355.

843 Rabosky, D. L., and I. J. Lovette. 2008a. Density-dependent diversification in North American wood 844 warblers. P. Roy. Soc. B-Biol. Sci. 275:2363-2371.

845 Rabosky, D. L., and I. J. Lovette. 2008b. Explosive evolutionary radiations: decreasing speciation or 846 increasing extinction through time? Evolution 62:1866-1875.

847 Rabosky, D. L., F. Santini, J. Eastman, S. A. Smith, B. Sidlauskas, J. Chang, and M. E. Alfaro. 2013. 848 Rates of speciation and morphological evolution are correlated across the largest vertebrate 849 radiation. Nat. Communications 4:1-8.

850 Rabosky, D. L., M. Grundler, C. Anderson, J. J. Shi, J. W. Brown, H. Huang, and J. G. Larson. 2014. 851 BAMMtools: an R package for the analysis of evolutionary dynamics on phylogenetic trees. 
Methods Ecol. Evol. 5:701-707.

853 Rage, J.-C., and Z. Roček. 2003. Evolution of anuran assemblages in the Tertiary and Quaternary of

854 Europe, in the context of palaeoclimate and palaeogeography. Amphibia-Reptilia 24:133-167.

855 Rambaut, A., and A. J. Drummond. 2012a. LogCombiner v1.7.5. Computer program and

856 documentation distributed by the author. Available from http://beast.bio.ed.ac.uk/LogCombiner

$857 \quad$ (last accessed on 26 August 2013).

858 Rambaut, A., and A. J. Drummond. 2012b. TreeAnnotator v1.7.5. Computer program and

859 documentation distributed by the author.http://beast.bio.ed.ac.uk/TreeAnnotator. (Accessed on

86026 August 2013).

861 Raven, P. H., and D. I. Axelrod. 1974. Angiosperm biogeography and past continental movements.

862 Ann. Miss. Bot. Gard. 61:539-673.

863 Räsänen, K., F. Söderman, A. Laurila, and J. Merilä. 2008. Geographic variation in maternal

864 investment: acidity affects egg size and fecundity in Rana arvalis. Ecology 89:2553-2562.

865 Reid, N. M. 2014. bGMYC: A Bayesian MCMC implementation of the general mixed Yule-

866 coalescent model for species delimitation. R package version 1.0.2.

867 Reid, N. M., and B. C. Carstens. 2012. Phylogenetic estimation error can decrease the accuracy of

868 species delimitation: a Bayesian implementation of the general mixed Yule-coalescent model.

$869 \quad$ BMC Evol. Biol. 12:196.

870 Richards, P. W. 1973. Africa, the “odd man out.” Pp. 21-26 in B. J. Meggers, S. A. Edwards, and W.

871 D. Duckworth, eds. Tropical forest ecosystems in Africa and South America: a comparative

872 review. Smithsonian Institution Press, Washington.

873 Robichaux, R. H., G. D. Carr, M. Liebman, and R. W. Pearcy. 1990. Adaptive radiation of the

874 hawaiian Silversword alliance (Compositae-Madiinae): ecological, morphological, and

875 physiological diversity. Ann. Miss. Bot. Gard. 77:64-72.

876 Rödel, M.-O. 2000. Herpetofauna of West Africa, Vol. I: Amphibians of the West African savanna. 
Rödel, M.-O., and W. R. Branch. 2003. Herpetological survey of the Haute Dodo and Cavally forests, western Ivory Coast, Part I: Amphibians. Salamandra 38:213-232.

Roelants, K., D. J. Gower, M. Wilkinson, S. P. Loader, S. D. Biju, K. Guillaume, and L. Moriau. 2007. Global patterns of diversification in the history of modern amphibians. P. Natl. Acad. Sci. USA 104:887-892.

Roff, D. A. 2002. Life history evolution. Sinauer Associates, Incorporated, Sunderland, MA.

884 Rowe, K. C., K. P. Aplin, P. R. Baverstock, and C. Moritz. 2011. Recent and rapid speciation with limited morphological disparity in the genus Rattus. Syst. Biol. 60:188-203.

Ruta, M., K. D. Angielczyk, J. Fröbisch, and M. J. Benton. 2013. Decoupling of morphological disparity and taxic diversity during the adaptive radiation of anomodont therapsids. P. Roy.

Schenk, J. J., K. C. Rowe, and S. J. Steppan. 2013. Ecological opportunity and incumbency in the Soc. B-Biol. Sci. 280:20131071.

Salisbury, C. L., N. Seddon, C. R. Cooney and J. A. Tobias. 2012. The latitudinal gradient in dispersal constraints: ecological specialisation drives diversification in tropical birds. Ecol.

Schweizer, M., S. T. Hertwig, and O. Seehausen. 2014. Diversity versus disparity and the role of ecological opportunity in a continental bird radiation. J. Biogeogr. 41:1301-1312. radiation of modern cetaceans. P. Roy. Soc. B-Biol. Sci. 277:3097-3104. 
902 Slingsby, J. A., M. N. Britton, and G. A. Verboom. 2014. Ecology limits the diversity of the Cape

903 flora: phylogenetics and diversification of the genus Tetraria. Mol. Phylogenet. Evol. 72:61-

90470 .

905 Steelman, J. T., and P. D. Danley. 2003. The stages of vertebrate evolutionary radiation. Trends Ecol.

$906 \quad$ Evol. 18:126-131.

907 Steppan, S. J., C. Zawadzki, and L. R. Heaney. 2003. Molecular phylogeny of the endemic Philippine

908 rodent Apomys (Muridae) and the dynamics of diversification in an oceanic archipelago. Biol.

909 J. Linn. Soc. 80:699-715.

910 Tandy, M., and R. Keith. 1972. Bufo of Africa. Pp. 119-170 in W. F. Blair, ed. Evolution in the

911 Genus Bufo. University of Texas Press, Texas.

912 Tihen, J. A. 1962. A review of New World fossil bufonids. Am. Midl. Nat. 1-50.

913 Tihen, J. A. 1951. Anuran remains from the Miocene of Florida, with the description of a new

914 species of Bufo. Copeia 1951:230-235.

915 Tolley, K. A., A. L. De Villers, M. I. Cherry, and G. J. Measey. 2010. Isolation and high genetic

916 diversity in dwarf mountain toads (Capensibufo) from South Africa. Biol. J. Linn. Soc.

$917 \quad 100: 822-834$.

918 Van Bocxlaer, I., K. Roelants, S. D. Biju, J. Nagaraju, and F. Bossuyt. 2006. Late Cretaceous

$919 \quad$ vicariance in Gondwanan Amphibians. PLoS ONE 1:e74.

920 Van Bocxlaer, I., S. P. Loader, K. Roelants, S. D. Biju, M. Menegon, and F. Bossuyt. 2010. Gradual

921 adaptation toward a range-expansion phenotype initiated the global radiation of toads. Science

$922 \quad 327: 679-682$.

923 Vences, M., D. R. Vieites, F. Glaw, H. Brinkmann, J. Kosuch, M. Veith, and A. Meyer. 2003.

924 Multiple overseas dispersal in amphibians. P. Roy. Soc. B-Biol. Sci. 270:2435-2442.

925 Von Rintelen, K., M. Glaubrecht, C. D. Schubart, A. Wessel and T. Von Rintelen, von. 2010.

926 Adaptive radiation and ecological diversification of Sulawesi's ancient lake shrimps. Evolution, 
$927 \quad 64: 3287-3299$.

928 Whittaker, R. J., and J. M. Fernandez-Palacios. 2007. Island biogeography: ecology, evolution, and 929 conservation. Oxford University Press, Oxford.

930 Wilgenbusch, J. C., D. L. Warren, and D. L. Swofford. 2004. AWTY: A system for graphical 931 exploration of MCMC convergence in Bayesian phylogenetic inference.

932 http://ceb.csit.fsu.edu/awty (last accessed on 26 August 2013).

933 Yoder, A. D., E. Clancey, S. des Roches, J. M. Eastman, A. H. Gentry, W. Godsoe, T. J. Hagey, D.

934 Jochimsen, B. P. Oswald, J. Robertson, B. A. J. Sarver, J. J. Schenk, S. F. Spear, and L. J.

935 Harmon. 2010. Ecological opportunity and the origin of adaptive radiations. J. Evolution. Biol. $936 \quad 23: 1581-1596$.

937

938 


\section{Figure legends}

940 Figure 1: MCC tree for Bufonidae recovered from time-calibrated Bayesian MCMC tree searches

941 using BEAST under a birth-death uncorrelated lognormal relaxed clock model. Node support below

942 posterior probabilities of 0.9 are indicated by grey squares and node bars show the $95 \%$ highest

943 posterior density of divergence times for key nodes; the origin of the two African clades (red) and the

944 fossil calibration points (green), A: the origin of the Rhinella marina clade, B: the most recent

945 common ancestor for Anaxyrus and Incilius C: the origin of the Bufo bufo group and D: the origin of

946 the Bufotes viridis group. The first African radiation (FAR) is colour-coded blue and the second

947 African radiation (SAR) is colour-coded green, with the insert depicting the geographic distribution

948 of these two clades and a representative per genus (sizes approximately to relative scale).

950 Figure 2: Lineage through time plots for the bGMYC tree (green) the CRS tree (yellow/orange) and

951 the median of 1000 Yule simulations for a tree with 89 taxa (grey/black). Shading marks the $95 \%$

952 quantiles of posterior and simulated trees.

954 Figure 3: Diversification dynamics for the bGMYC (green) and the CRS tree (yellow) using the

955 BAMM software package. a) Posterior distribution of regimes with different numbers of rate

956 processes (including the root process). b) Speciation and extinction rates through time, where shaded

957 areas denote the $95 \%$ quantiles on the posterior distribution of the rates.

959 Figure 4: Rate dynamics (beta) through time for body size (full line) and size-free clutch (long

960 dashes) and egg (short dashes) size. Shaded areas denote the $95 \%$ quantiles on the posterior

961 distribution of rates. 
963 Figure 5: Disparity through time (DTT) plots for a) body size and b) size-corrected clutch size and c)

964 size-corrected egg size. Solid lines represent the observed DTT using the MCC tree and grey lines are

965 the observed values for a subsample of 1000 post-burnin posterior trees. Dashed lines represent the

966 median DTT under a Brownian motion model simulation with 95\% confidence intervals as the light

967 grey translucent polygon.

968

969 Figure 6: Probability density plots of posterior distribution of speciation rates associated with shifts

970 from habitat generalists (dark) to specialists (light), estimated using MCMC-BiSSE using the a)

971 bGMYC tree and b) CRS tree. Dashed lines are maximum likelihood rate estimates and inserted

972 phylogenies depict the coding of tip states.

973 


\section{Supporting information}

975 Supporting Information S1: Extended version of Methods section

976

977 Supporting Information S2: GenBank numbers and voucher information for individuals included in 978 the phylogenetic reconstructions.

979

980 Supporting Information S3: MCC tree for Bufonidae (Global Tree) recovered from time-calibrated

981 Bayesian MCMC tree searches using BEAST under a birth-death uncorrelated lognormal relaxed 982 clock model. Nodes are annotated with posterior probabilities.

984 Supporting Information S4: MCC tree for the first African radiation (FAR tree) of bufonids, 985 recovered from time-calibrated Bayesian MCMC tree searches using BEAST under a birth-death 986 uncorrelated lognormal relaxed clock model. Nodes are annotated with posterior probabilities and 987 clades in green are delimited units based on a bGMYC species discovery analysis at a 0.01 threshold. 988

989 Supporting Information S5: Phylogenetic tree recovered from pruning the FAR tree to include only a 990 single representative of each currently recognized species (CRS tree).

991

992 Supporting Information S6. Tree recovered from pruning the FAR tree to include only a single 993 representative of each bGMYC delimited element (bGMYC tree).

995 Supporting Information S7. Repeat of rate dynamics analyses (BAMM and BiSSE) using truncated 996 bGMYC tree.

998 Supporting Information S8. Investigating the effects of bGMYC oversplitting. 
1 Table 1. Summary statistic of diversification models fitted to the branching times of the a) species

2 delimited bGMYC tree and b) CRS tree. The models tested are pure-birth (PB) and birth-death (BD)

3 with constant rates, $\mathrm{PB}$ with an exponential speciation rate ( $\mathrm{PB} \lambda \mathrm{exp}), \mathrm{BD}$ with a constant speciation

4 rate and exponential extinction rates (BDicst- $\mu \exp ), \mathrm{BD}$ with an exponential speciation rate and

5 constant extinction rate $(\mathrm{BD} \lambda \exp -\mu \mathrm{cst})$ and $\mathrm{BD}$ with both exponential speciation and extinction rates

6 (BD $\lambda \operatorname{exp-\mu exp).~Parameters~refer~to~the~estimated~rates~at~the~tips~and~the~corresponding~time-~}$

7 variation parameter.

\begin{tabular}{|c|c|c|c|c|c|c|}
\hline Model & $\lambda$ Parameters & $\mu$ Parameters & LH & $\mathrm{AICc}$ & $\triangle \mathrm{AICc}$ & Aw \\
\hline \multicolumn{7}{|c|}{ A) bGMYC tree } \\
\hline \multicolumn{2}{|c|}{ Constant Rate Models } & 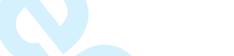 & & & & \\
\hline PB & 0.137 & & -298.691 & 599.421 & - & 0.501 \\
\hline $\mathrm{BD}$ & 0.137 & $<0.001$ & -298.691 & 601.503 & 2.081 & 0.177 \\
\hline \multicolumn{7}{|c|}{ Variable Rate Models } \\
\hline PB $\lambda \exp$ & $0.136 ; 0.002$ & & -298.685 & 601.491 & 2.069 & 0.178 \\
\hline BD $\lambda$ cst- $\mu \exp$ & 0.137 & $<0.001 ;-0.218$ & -298.691 & 603.626 & 4.205 & 0.061 \\
\hline BD $\lambda \exp -\mu c s t$ & $0.136 ; 0.002$ & $<0.001$ & -298.685 & 603.614 & 4.193 & 0.062 \\
\hline $\mathrm{BD} \lambda \exp -\mu \exp$ & $0.135 ; 0.002$ & $<0.001 ;-0.056$ & -298.685 & 605.782 & 6.360 & 0.021 \\
\hline
\end{tabular}

\section{B) CRS tree}

\begin{tabular}{|c|c|c|c|c|c|c|}
\hline \multicolumn{7}{|c|}{ Constant Rate Models } \\
\hline PB & 0.121 & & -191.348 & 384.765 & - & 0.452 \\
\hline $\mathrm{BD}$ & 0.121 & $<0.001$ & -191.348 & 386.907 & 2.142 & 0.155 \\
\hline \multicolumn{7}{|c|}{ Variable Rate Models } \\
\hline РB $\lambda \exp$ & $0.106 ; 0.015$ & & -191.008 & 386.226 & 1.460 & 0.218 \\
\hline BD $\lambda$ cst- $\mu \exp$ & 0.146 & $378.188 ;-2225.174$ & -190.891 & 388.210 & 3.445 & 0.081 \\
\hline BD $\lambda \exp -\mu c s t$ & $0.106 ; 0.015$ & $<0.001$ & -191.008 & 388.444 & 3.679 & 0.072 \\
\hline BD $\lambda \exp -\mu \exp$ & $0.106 ; 0.015$ & $<0.001 ; 0.005$ & -191.008 & 390.743 & 5.977 & 0.023 \\
\hline
\end{tabular}


Table 2. Model fit comparison for evolutionary dynamics of life history traits a) body size, b) clutch size and c) egg size. The models tested are Brownian motion (BM), Ornstein-Uhlenbeck (OU), Pagel's lambda $(\lambda)$, early burst (EB), linear variable rate (LIN) and Pagel's delta $(\delta)$. Parameters refer to trait evolution rate estimates at the root (z0), attraction strength of the OU model $(\alpha)$, Pagel's branch length transformation $(\lambda)$, rate change parameter for the EB model (a), slope parameter for the LIN model (b) and Pagel's delta $(\delta)$.

\begin{tabular}{|c|c|c|c|c|c|c|}
\hline Model & Rate & Parameters & $\operatorname{lnL}$ & AIC & $\Delta \mathrm{AIC}$ & $\mathrm{AW}$ \\
\hline \multicolumn{7}{|c|}{ a) Body size } \\
\hline BM & constant & $\mathrm{z} 0=1.692$ & 13.392 & -22.785 & 9.666 & 0.008 \\
\hline OU & constant & $\mathrm{z} 0=1.697 ; \alpha=0.034$ & 15.339 & -24.677 & 7.774 & 0.019 \\
\hline$\lambda$ & constant & $z 0=1.689 ; \lambda=0.808$ & 19.226 & -32.451 & - & 0.950 \\
\hline EB & variable & $\mathrm{z} 0=1.692 ; \mathrm{a}=-1 \mathrm{e}-6$ & 13.392 & -20.785 & 11.666 & 0.003 \\
\hline LIN & variable & $\mathrm{z} 0=1.698 ; b=0.217$ & 14.745 & -23.490 & 8.961 & 0.011 \\
\hline$\delta$ & variable & $\mathrm{z} 0=1.702 ; \delta=1.849$ & 14.635 & -23.271 & 9.180 & 0.010 \\
\hline \multicolumn{7}{|c|}{ b) Clutch size } \\
\hline BM & constant & $\mathrm{z} 0=5.160 \mathrm{e}-11$ & -18.984 & 41.969 & - & 0.328 \\
\hline OU & constant & $\mathrm{z} 0=0.005 ; \alpha=0.007$ & -18.908 & 43.817 & 1.848 & 0.130 \\
\hline$\lambda$ & constant & $\mathrm{z} 0=-0.001 ; \lambda=0.965$ & -18.635 & 43.270 & 1.301 & 0.171 \\
\hline EB & variable & $\mathrm{z} 0=-3.169 \mathrm{e}-7 ; \mathrm{a}=-1 \mathrm{e}-6$ & -18.984 & 43.969 & 2.000 & 0.121 \\
\hline LIN & variable & $\mathrm{z} 0=0.004 ; \mathrm{b}=0.015$ & -18.92 & 43.840 & 1.871 & 0.129 \\
\hline$\delta$ & variable & $\mathrm{z} 0=0.003 ; \delta=1.079$ & -18.97 & 43.940 & 1.971 & 0.122 \\
\hline \multicolumn{7}{|c|}{ c) Egg size } \\
\hline $\mathrm{BM}$ & constant & $z 0=-1.707 e-11$ & 37.909 & -71.818 & 1.785 & 0.115 \\
\hline OU & constant & $z 0=-0.013 ; \alpha=0.041$ & 39.588 & -73.175 & 0.428 & 0.226 \\
\hline$\lambda$ & constant & $z 0=-0.001 ; \lambda=0.8$ & 39.801 & -73.603 & - & 0.280 \\
\hline EB & variable & $\mathrm{z} 0=-1.180 \mathrm{e}-7 ; \mathrm{a}=-1 \mathrm{e}-6$ & 37.909 & -69.818 & 3.785 & 0.042 \\
\hline LIN & variable & $\mathrm{z} 0=-0.013 ; \mathrm{b}=98.913$ & 39.271 & -72.542 & 1.061 & 0.165 \\
\hline$\delta$ & variable & $\mathrm{z} 0=-0.016 ; \delta=2.254$ & 39.31 & -72.620 & 0.983 & 0.171 \\
\hline
\end{tabular}




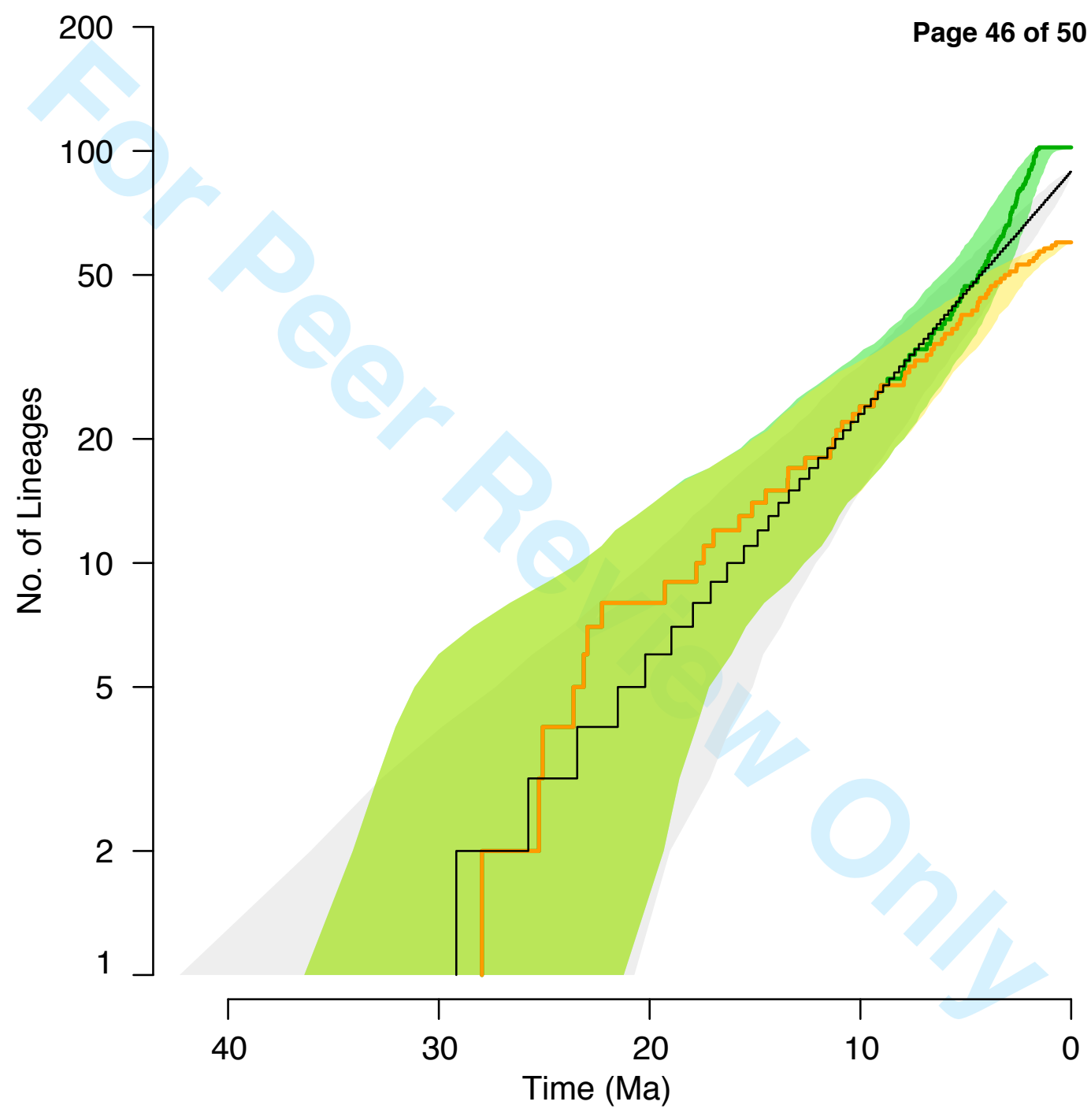




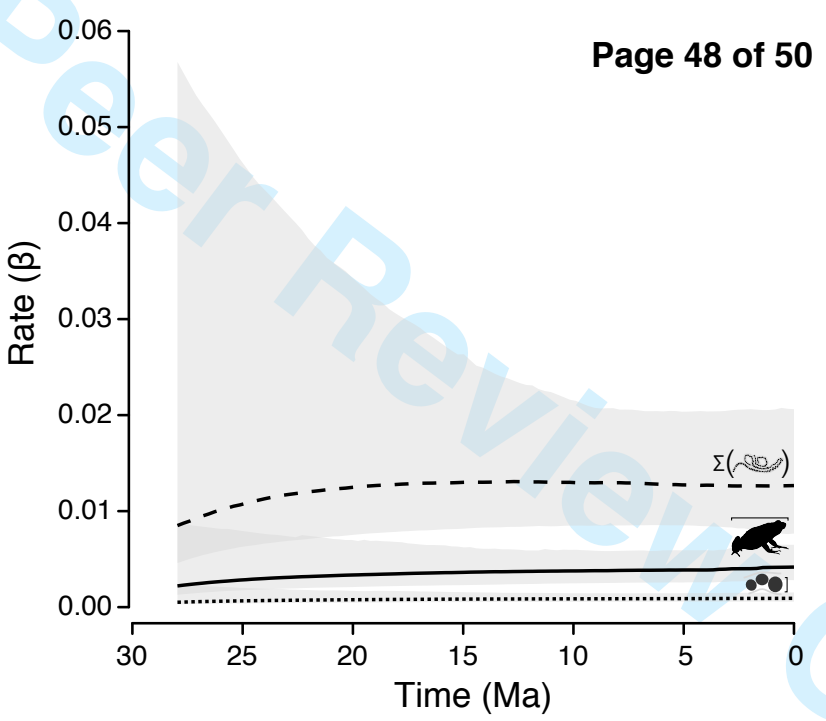



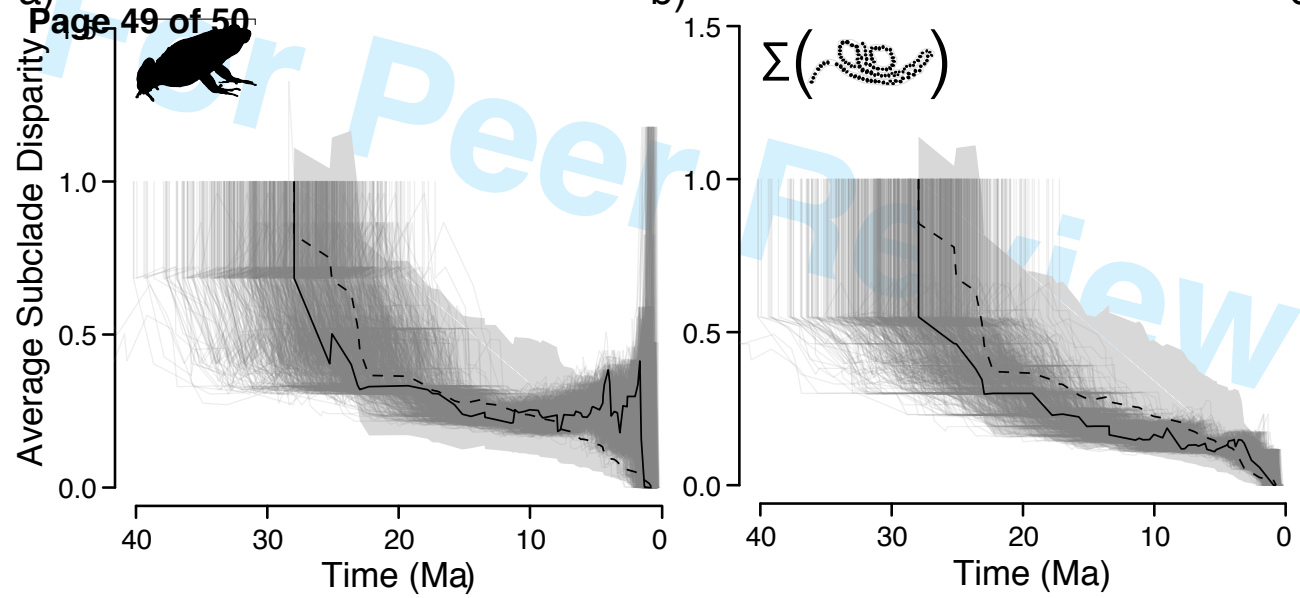

C)

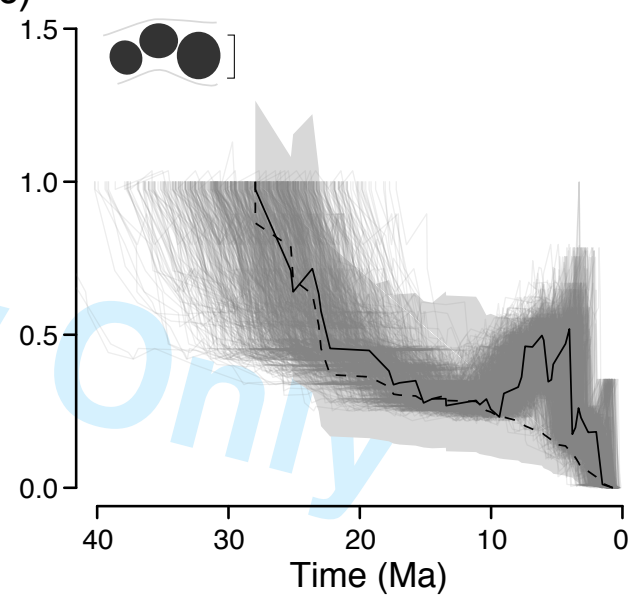


a)

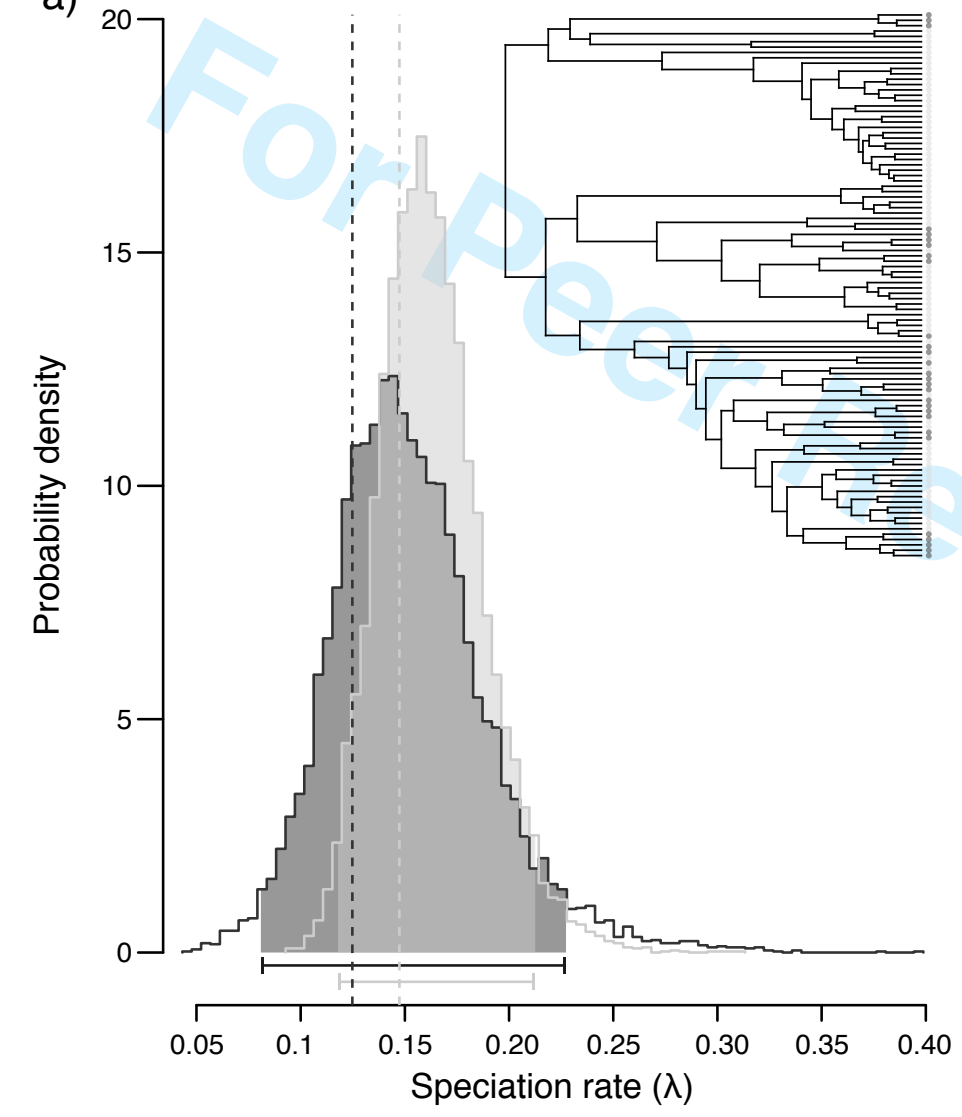

b)

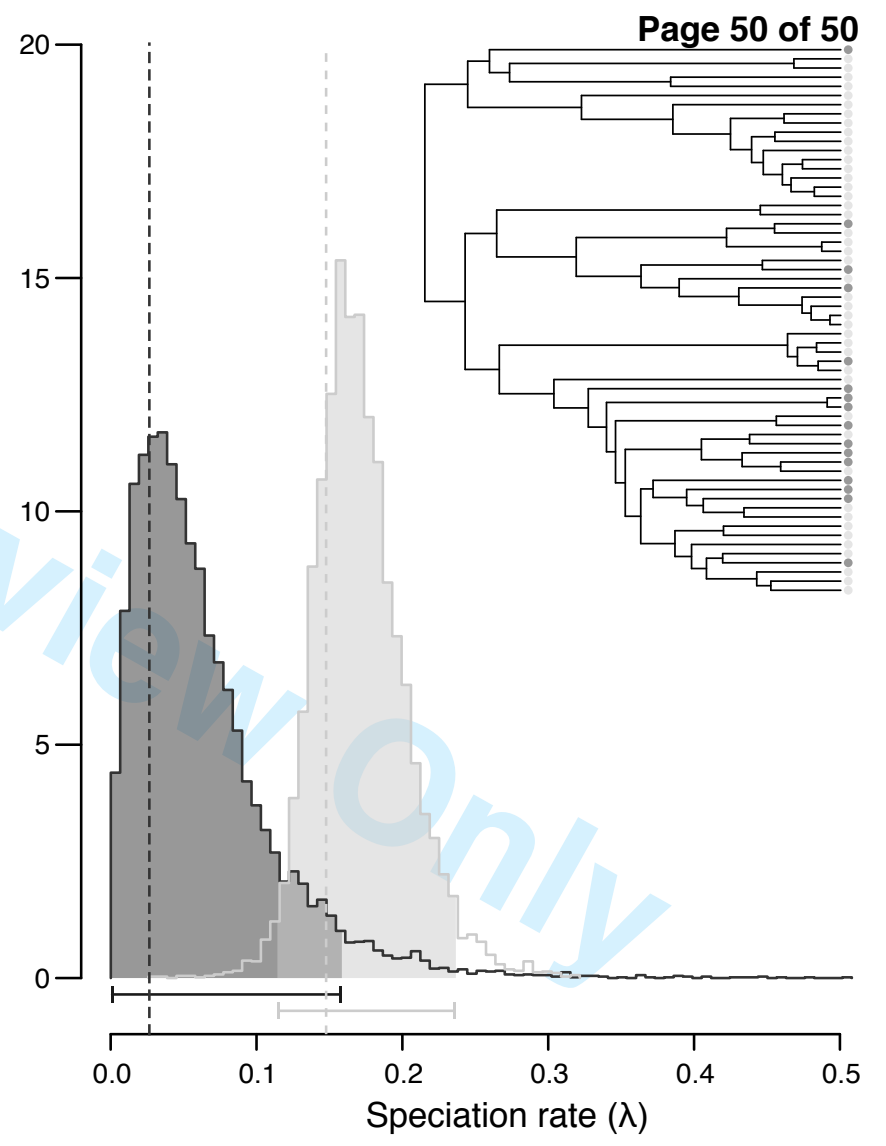

